\title{
Muscarinic Attenuation of Mnemonic Rule Representation in Macaque Dorsolateral Prefrontal Cortex during a Pro- and Anti-Saccade Task
}

\author{
Alex J. Major, ${ }^{1 \star}$ Susheel Vijayraghavan, ${ }^{2 \star}$ and Stefan Everling ${ }^{1,2,3}$ \\ ${ }^{1}$ Graduate Program in Neuroscience, ${ }^{2}$ Department of Physiology and Pharmacology, and ${ }^{3}$ Robarts Research Institute, University of Western Ontario, \\ London, Ontario N6A 5B7, Canada
}

\begin{abstract}
Maintenance of context is necessary for execution of appropriate responses to diverse environmental stimuli. The dorsolateral prefrontal cortex (DLPFC) plays a pivotal role in executive function, including working memory and representation of abstract rules. DLPFC activity is modulated by the ascending cholinergic system through nicotinic and muscarinic receptors. Although muscarinic receptors have been implicated in executive performance and gating of synaptic signals, their effect on local primate DLPFC neuronal activity in vivo during cognitive tasks remains poorly understood. Here, we examined the effects of muscarinic receptor blockade on rule-related activity in the macaque prefrontal cortex by combining iontophoretic application of the general muscarinic receptor antagonist scopolamine with single-cell recordings while monkeys performed a mnemonic rule-guided saccade task. We found that scopolamine reduced overall neuronal firing rate and impaired rule discriminability of task-selective cells. Saccade and visual direction selectivity measures were also reduced by muscarinic antagonism. These results demonstrate that blockade of muscarinic receptors in DLPFC creates deficits in working memory representation of rules in primates.
\end{abstract}

Key words: DLPFC; iontophoresis; macaque; muscarinic; rule; saccade

\section{Significance Statement}

Acetylcholine plays a pivotal role in higher-order cognitive functions, including planning, reasoning, impulse-control, and making decisions based on contingencies or rules. Disruption of acetylcholine function is central to many psychiatric disorders manifesting cognitive impairments, including Alzheimer's disease. Although much is known about the involvement of acetylcholine and its receptors in arousal and attention, its involvement in working memory, an essential short-term memory component of cognition dependent on the integrity of prefrontal cortex, remains poorly understood. Herein, we explored the impact of suppressing acetylcholine signaling on neurons encoding memorized rules while macaque monkeys made responses based on those rules. Our findings provide insights into the neural mechanisms by which a disruption in acetylcholine function impairs working memory in the prefrontal cortex.

\section{Introduction}

Flexible response to sensory stimuli is a hallmark of intelligent behavior. Appreciation of rules and context, and other executive functions, including working memory (WM), attention, and rea-

Received June 26, 2015; revised Oct. 8, 2015; accepted Oct. 31, 2015.

Author contributions: A.J.M., S.V., and S.E. designed research; A.J.M. and S.V. performed research; A.J.M., S.V., and S.E. analyzed data; A.J.M., S.V., and S.E. wrote the paper.

This work was supported by Canadian Institutes of Health Research Operating Grant to S.E.

The authors declare no competing financial interests.

*A.J.M. and S.V. contributed equally to this work.

Correspondence should be addressed to Dr. Stefan Everling, Centre for Functional and Metabolic Mapping,

Robarts Research Institute, 1151 Richmond Street North, London, ON N6A 5B7, Canada. E-mail: severlin@uwo.ca.

DOI:10.1523/JNEUROSCI.2454-15.2015

Copyright $\odot 2015$ the authors $\quad 0270-6474 / 15 / 3516064-13 \$ 15.00 / 0$ soning, are dependent on prefrontal cortex (PFC) (Miller and Cohen, 2001).

Through reciprocal connectivity with sensory, parietal, premotor, subcortical, and other prefrontal regions (Miller and Cohen, 2001), and extensive local connectivity that can generate recurrent activity (Levitt et al., 1993; Pucak et al., 1996), the dorsolateral PFC (DLPFC) is a suitable substrate for holding representations in WM (Goldman-Rakic, 1995) and facilitating contextually appropriate responses. DLPFC exhibits robust postsensory behaviorally relevant activity (Fuster and Alexander, 1971, Funahashi et al., 1989) with distractor resistance (Miller et al., 1996, Everling et al., 2002, Suzuki and Gottlieb, 2013, Jacob and Nieder, 2014), forming a "mental sketchpad," a component of formal models of executive function (Baddeley and Hitch, 1974). This sustained activity is considered the cellular basis of 
WM (Goldman-Rakic, 1995). DLPFC neurons represent information on task-set (Sakai, 2008) and display discriminable rule-contingent activity in context-dependent tasks (White and Wise, 1999; Asaad et al., 2000; Wallis et al., 2001; Everling and DeSouza, 2005, Mian et al., 2014). Lesion studies in macaques and humans (Milner, 1963; Guitton et al., 1985; Funahashi et al., 1993 ) suggest that intact DLPFC is necessary for cognitive control. Buckley et al. (2009) found that focal principal sulcal lesions, but not orbitofrontal or anterior cingulate cortical lesions, affected performance in a rule-guided analog of the Wisconsin Card Sorting Test. DLPFC dysfunction contributes to cognitive deficits observed in psychiatric disorders, such as schizophrenia and Alzheimer's disease (Perlstein et al., 2001; Bussière et al., 2003; Schroeter et al., 2012; Konopaske et al., 2014).

The DLPFC receives substantial input from ascending monoaminergic and cholinergic systems (Robbins, 2005). The cholinergic system acts upon cortical nicotinic and muscarinic receptors (Mash et al., 1988; Han et al., 2000) and releases acetylcholine (ACh) based on attentional effort (Kozak et al., 2006) and arousal (Phillis, 1968). Numerous studies have found that muscarinic antagonist scopolamine attenuates various behavioral measures (Taffe et al., 1999; for review, see Klinkenberg and Blokland, 2010), including WM (Green et al., 2005) and representation of task rules (Saar et al., 2001; Thomas et al., 2008; Snyder et al., 2014). Using a cholinergic-selective immunotoxin, Croxson et al. (2011) found that cholinergic deafferentation of DLPFC selectively affects spatial WM performance while sparing other cognitively demanding tasks involving strategy implementation and episodic memory.

Muscarinic antagonism can elicit psychotic states reminiscent of schizophrenia, which has been termed anti-muscarinic syndrome (Barak and Weiner, 2009). Schizophrenics homozygous for an M1 receptor (M1R) polymorphism have deficits in Wisconsin Card Sorting Test performance (Liao et al., 2003; Scarr et al., 2012), and muscarinic enhancers are being explored intensively for amelioration of cognitive deficits in schizophrenia and Alzheimer's disease (Shekhar et al., 2008).

Although behavioral outcomes of systemic muscarinic antagonism have been extensively explored, there are fewer studies examining effects of scopolamine on DLPFC neuronal physiology. Zhou et al. (2011) reported marked suppression of DLPFC neurons in the memory period with concomitant behavioral degradation upon systemic scopolamine administration. However, because scopolamine was systemically administered, it is unclear whether the DLPFC neuronal suppression involved local muscarinic modulation or was a consequence of dysregulation of inputs to DLPFC circuitry. Here, we performed concurrent in vivo single-cell electrophysiology and iontophoresis of scopolamine in DLPFC of monkeys performing a rule-guided WM task to investigate the role of muscarinic receptors in the maintenance of task rules. The task required subjects to execute a pro- or antisaccade based upon a previously remembered rule (prompted by an initial visual cue). DLPFC neuronal activity shows mnemonic representations of rules used to direct saccade outcome (Everling and DeSouza, 2005; Johnston and Everling, 2006; Johnston et al., 2009), and deactivation of the DLPFC impairs performance of this task (Koval et al., 2011; Hussein et al., 2014).

\section{Materials and Methods}

Experimental procedures were performed on two adult male rhesus macaque monkeys (Macaca mulatta) in accordance with the Canadian Council of Animal Care policy and a protocol approved by the Animal Use Subcommittee of the University of Western Ontario Council on
Animal Care. Both animals had a plastic head restraint and plastic recording chambers implanted above their right lateral PFC as described previously (Skoblenick and Everling, 2012).

Behavioral task. Both animals were trained on the gap variant of a proand anti-saccade task (Fig. 1A). Monkeys were seated in a primate chair in a shielded chamber with their heads restrained and faced a 21 inch CRT monitor $51 \mathrm{~cm}$ in front of them. Horizontal and vertical eye movements were recorded at $1 \mathrm{kHz}$ with an EyeLink 1000 infrared eye tracker and software package (SR Research). The task, behavior monitoring, and reward delivery were controlled using CORTEX (National Institutes of Mental Health). Trials began with presentation of a central gray filled fixation circle $\left(0.5^{\circ}\right.$ diameter $)$. After an initial $300 \mathrm{~ms}$ fixation period, the fixation stimulus briefly changed color to red or green for $100 \mathrm{~ms}$, indicating the task rule (pro- or anti-saccade) of the current trial. Rule colors were counterbalanced between subjects. The subjects were required to remember the rule through a delay period $(800-1300 \mathrm{~ms})$ during which the fixation spot reverted to gray. The fixation spot was extinguished for $150-300 \mathrm{~ms}$ (gap period), and a peripheral stimulus $\left(17.5^{\circ}\right.$ from center, $0.5^{\circ}$ diameter) was then presented. The gap was introduced to increase task difficulty (Everling et al., 1998). The subjects were required to make the appropriate saccade toward (pro-saccade) or away from (antisaccade) the stimulus, depending on the current trial's rule. Rule and stimulus combinations were presented in pseudorandom order. To obtain a liquid reward, the subjects had to maintain fixation during the fixation, cue, and delay periods, make the appropriate saccade within 500 $\mathrm{ms}$, and maintain fixation on the stimulus (or blank space in the case of anti-saccade trials) for $120 \mathrm{~ms}$. Trials were separated by a $1700-2200 \mathrm{~ms}$ intertrial interval (ITI). Performance was defined as the proportion of completed trials (i.e., animal did not break central fixation until stimulus period) that resulted in a correct saccade. Saccade onset was defined as the moment eye velocity surpassed $30 \%$, and saccadic reaction time (SRT) was defined as the time from the peripheral stimulus onset to saccade onset.

One of the confounds of this color-cued task is that differential activity related to the rule during the presentation of the colored cue and the subsequent delay epoch may merely reflect a WM representation for the color of the rule-cue rather than being a WM representation of the abstract rule. We think this is unlikely based on previous work in our laboratory examining the activity of neurons in this area during a variant of the pro- and anti-saccade task that does not involve explicit rule instruction (Everling and DeSouza, 2005; Johnston et al., 2007). In this task variant, monkeys were trained to perform alternating blocks of pro- and anti-saccade trials without any explicit color cue instructing them on the appropriate response. Instead, when the block changes to the other rule, the monkeys would initially make an incorrect response based on the previous rule, but upon receiving no reward must switch to the updated block rule and appropriate response (pro- or anti-saccade) contingent on reward feedback. In this uncued version of the task (Everling and DeSouza, 2005; same DLPFC loci as the present study), DLPFC neurons consistently displayed differential activity for pro- and anti-saccades, which cannot be a consequence of WM for rule-cue color attributes because the fixation spot remains the same color (white) throughout the trial and rule representations are internally generated based on reward feedback.

In vivo extracellular recordings and iontophoresis. Scopolamine was iontophoretically administered using custom seven-barreled glass iontophoretic electrodes. The design and fabrication of the electrodes were similar to Vijayraghavan et al. (2007). A 50- $\mu$ m-pitch tungsten wire, 110 $\mathrm{mm}$ in length (Midwest Tungsten Service), was electrochemically etched (model EE-ID, Bak Electronics) using a sodium nitrite and potassium hydroxide solution as described previously (Thiele et al., 2006), creating a fine wire tip. This wire was inserted into the central barrel of a multibarreled pipette (Friedrich and Dimmock), and the assembly was pulled using a PMP107L-e Multipipette Puller (MicroData Instrument), resulting in a 10.5-cm-long electrode shaft and a thin glass tip on the order of 15-30 $\mu \mathrm{m}$. Typical impedances were between 0.5 and $1 \mathrm{M} \Omega$ (measured at $1 \mathrm{kHz}$; IMP-1, Bak Electronics). Neuronal signals were amplified, digitized, and filtered $(300 \mathrm{~Hz}-6 \mathrm{kHz}$, four-pole Bessel) with an OmniPlex Neural Data Acquisition System (Plexon) 


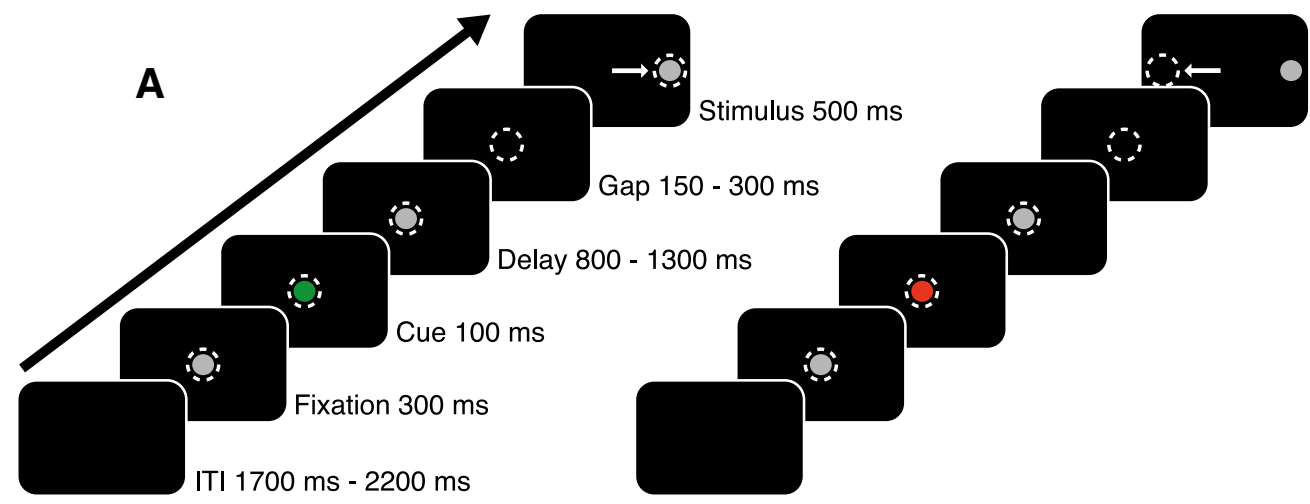

Pro-saccade

Anti-saccade

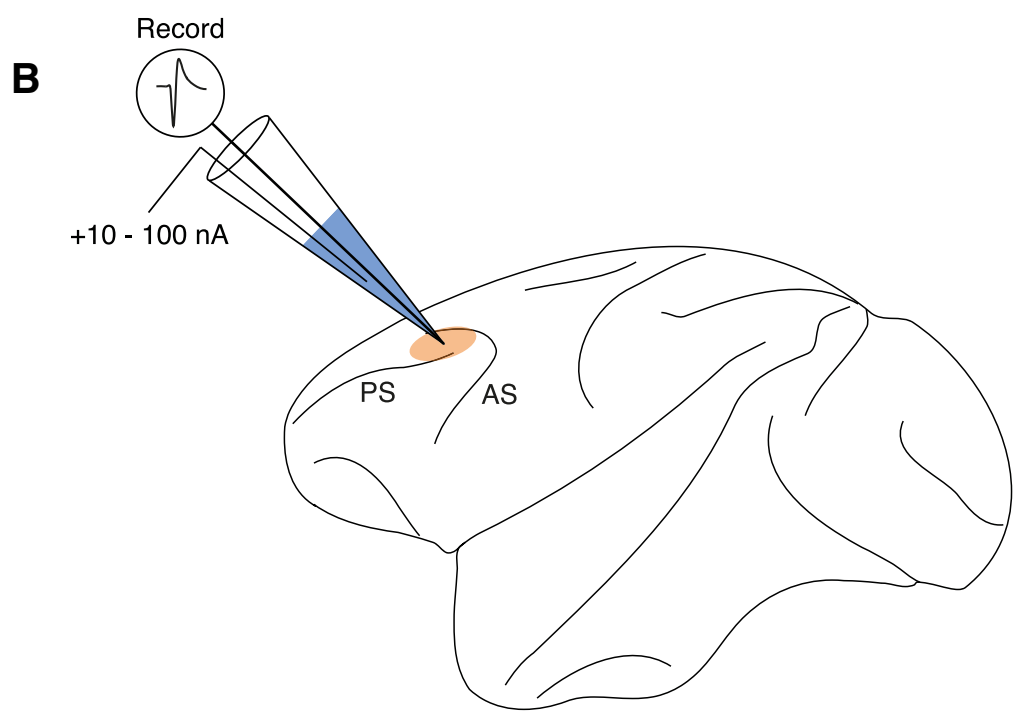

Figure 1. Experimental paradigm and recording technique. $A$, Schematic of representative pro- and anti-saccade trials. Animals were required to perform correct responses toward (pro-saccade) or away from (anti-saccade) a peripheral stimulus to receive liquid reward. Dashed circles represent gaze of the animal. Arrows indicate direction of saccade. Each trial is followed by a $1700-2200$ ms ITI. B, Single-unit extracellular recordings were performed in macaque DLPFC using glass iontophoretic electrodes. Beige area represents recording locus. Muscarinic antagonist scopolamine (represented in blue) is shown. AC, Arcuate sulcus; PS, principal sulcus.

Scopolamine hydrobromide (Tocris Bioscience; $100 \mathrm{~mm}$ in $\mathrm{pH} 3$ deionized water) was stored in $30 \mu \mathrm{l}$ aliquots at $-20^{\circ} \mathrm{C}$. Before use, scopolamine was thawed and inserted into peripheral glass capillaries of the iontophoretic electrode, then pushed to the tip of the electrode using compressed air. Tungsten wires (FHC) were inserted into each peripheral capillary and connected to a Neuro Phore BH-2 iontophoretic ejection system (Harvard Apparatus). DC impedances of drug barrels varied, typically between 50 and $300 \mathrm{M} \Omega$. The electrode was mounted on a hydraulic micromanipulator (MO-95, Narishige) and lowered into cortex through a 23-gauge dura-penetrating stainless steel guide tube. A plastic recording grid $(1 \mathrm{~mm}$ spacing; Crist Instruments) was used to guide chamber placement. A schematic of the approximate recording locus around the principal sulcus in $D L P F C$ is shown in Figure $1 B$. Constant ejection currents ranging from 10 to $100 \mathrm{nA}$ were manually set by the experimenter during the course of scopolamine conditions. Because we had no a priori predictions regarding the strength of potential scopolamine modulation of PFC neurons, we tested a broad range of scopolamine doses in this study. The median current strength of scopolamine ejection used in this study was $40 \mathrm{nA}$ (25th percentile, $20 \mathrm{nA}$; 75 th percentile, $60 \mathrm{nA}$ ). A retention current of $-8 \mathrm{nA}$ was passed over each drug barrel during control periods. Current balancing was not required at ejection currents of this magnitude (Vijayraghavan et al., 2007). At these currents, drug ejection did not create noise in the system or affect unit physiology (Vijayraghavan et al., 2007). After control periods of at least $10 \mathrm{~min}$, a drug condition followed with comparable duration. Multiple scopolamine doses and post-scopolamine recovery conditions were occasionally tested on the same neuron to observe dose-dependent effects on neuronal activity and drug specificity, respectively. Cells were rejected if a sufficient number of correct trials were not obtained (at least 8 per rule-saccade direction combination) or if control condition activity was $<1$ spikes/s.

Data analysis. Neuron waveforms were sorted using principal component cluster space segregation (Offline Sorter; Plexon). Data analysis was performed with custom-written programs in MATLAB (The MathWorks). Spike density functions were constructed by convolving spike trains with a $50 \mathrm{~ms}$ Gaussian activation function. Trialwise rasters and spike density functions were aligned to peripheral stimulus onset. The delay epoch was defined as time from cue offset to stimulus onset $+70 \mathrm{~ms}$ (i.e., to allow time for visual information to reach DLPFC; Johnston et al., 2009). Rule selectivities for control and drug conditions were evaluated using area under the receiver operating characteristic (AUROC), a nonparametric measure of discriminability between two distributions (Green and Swets, 1966). AUROCs (1000 steps) were computed using mean firing rate (FR) from pro-saccade rule trials and anti-saccade rule trials during the entire delay epoch. AUROC values range from 0 to 1 , with completely overlapping distributions having an AUROC of 0.5 , and distributions with greater FR for either pro-saccade or anti-saccade trials approaching values of 1 or 0 , respectively. The significance of the AUROC metric obtained was estimated using a bootstrapping procedure, whereby control trial FRs were randomly assigned to pro- or antisaccade rule trials and the AUROC for shuffled trial FR distributions was computed (Everling and DeSouza, 2005). A neuron's firing profile was 


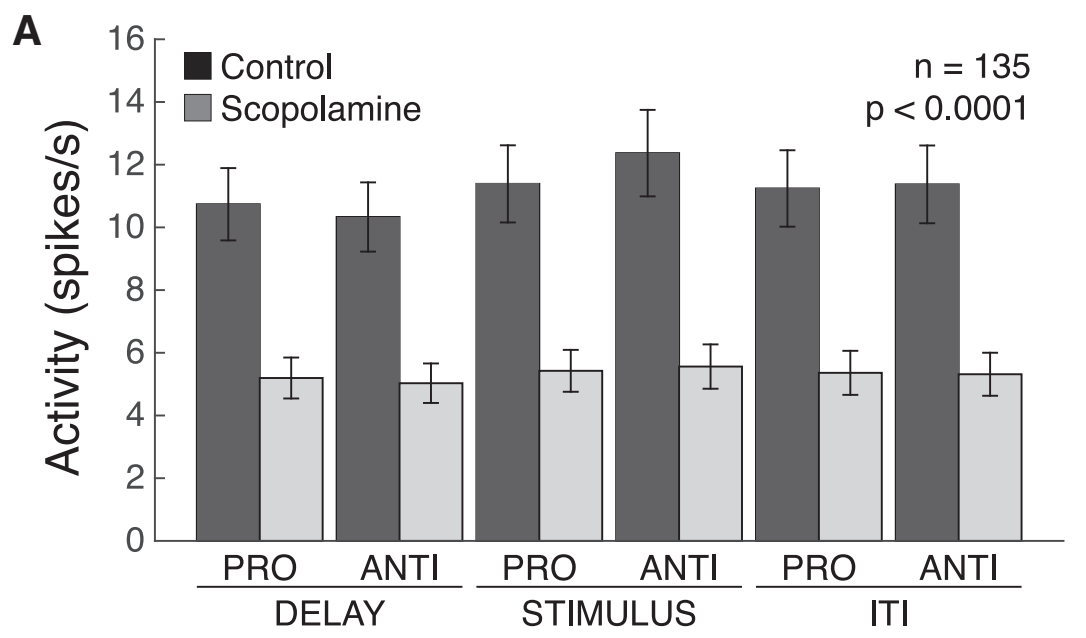

B

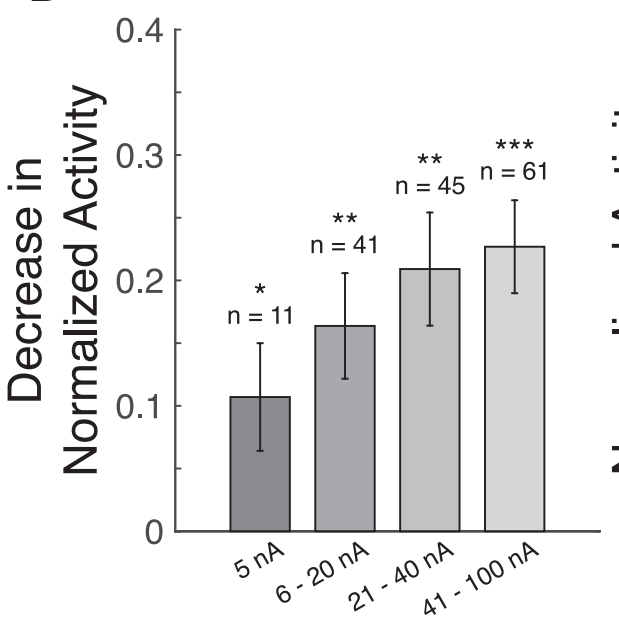

\section{C}

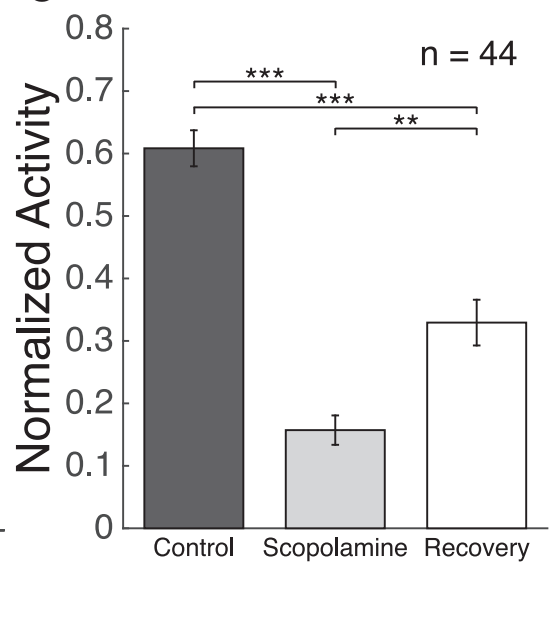

Figure 2. Effect of scopolamine on neuronal firing. $A$, Mean FRs from 135 PFC neurons (dark gray bars represent control; light dark gray bars represent scopolamine) in the delay, stimulus, and ITI epochs of the task. Scopolamine significantly decreased FRs of recorded neurons in both pro-saccade and anti-saccade trials in the delay, stimulus, and ITl epochs. The indicated significance value applies to all comparisons. $\boldsymbol{B}$, Decreases to normalized FRs for neurons onto which various doses of scopolamine were tested: $5 \mathrm{nA}$, $p=0.042 ; 6-20 \mathrm{nA}, p=0.00081 ; 21-40 \mathrm{nA}, p=0.00021 ; 41-100 \mathrm{nA}, p<0.0001$. C, Recovery of FR upon cessation of scopolamine ejection. Although recovery condition FR was significantly greater than scopolamine condition ( $p=0.00024)$, it did not reach control levels. This includes all cells given a recovery condition and a control mean $F R>1$ spikes/s. Error bars indicate SEM. ${ }^{*} p<0.05,{ }^{* *} p<0.01,{ }^{* * *} p<0.0001$ (Wilcoxon signed rank test with Holm-Bonferroni correction). FRs were normalized as described (see Materials and Methods).

deemed significantly selective if the original AUROC was $<5$ th percentile or $>95$ th percentile of the shuffled AUROCs from 10,000 iterations. For all neurons with a significantly selective AUROC, the rule eliciting greater FR during the delay epoch of the control condition was set as the preferred rule. The AUROCs of neurons with the preferred rule set as antisaccade were inverted $(1-$ AUROC), such that their AUROCs in the control condition were now also between 0.5 and 1 (i.e., AUROC values now represented selectivity for the preferred vs nonpreferred rule). The same analysis was performed during the stimulus epoch (stimulus onset $+70 \mathrm{~ms}$ to saccade onset $+120 \mathrm{~ms}$ ) for preferred and nonpreferred rule, saccade direction, and visual stimulus direction to evaluate selectivity and significance. As a decrease in AUROC can be explained by either decreased mean FR difference or increased trial-to-trial FR variance, the Fano factor was calculated to inspect changes to neuronal reliability. This was calculated as trialwise FR variance divided by the mean for control and drug epochs. Normalized population spike density functions across all rule-selective neurons were constructed in the delay epoch for the preferred and nonpreferred rule using the following:

$$
\mathrm{FR}^{\prime}=\frac{\mathrm{FR}-\mathrm{FR}_{\min }}{\mathrm{FR}_{\max }-\mathrm{FR}_{\min }}
$$

where $\mathrm{FR}_{\min }$ and $\mathrm{FR}_{\max }$ are the minimum and maximum of the smoothed spike density functions in both control and scopolamine conditions. Normalized spike density functions of all rule cells in the delay epoch were then averaged. Identical normalizations were performed for rule, directional, and visual neurons in the stimulus epoch.

\section{Results}

Combined single-neuron recordings and iontophoretic scopolamine applications were performed in 82 experimental sessions (44 from Monkey O, 38 from Monkey $\mathrm{T}$ ), and 135 total neurons were recorded (72 from Monkey O, 63 from Monkey T). Monkeys performed the behavioral saccade task during control and scopolamine conditions, each typically lasting a minimum of $10 \mathrm{~min}$. No significant differences in pro-saccade performance (control $86.5 \pm 1.1 \%$ vs scopolamine $87.5 \pm 0.9 \%, p=0.51$, Wilcoxon signed rank test) or anti-saccade SRT $(195.3 \pm 2.0 \mathrm{~ms}$ vs $197.0 \pm 2.2 \mathrm{~ms}, p=0.20)$ were observed during scopolamine conditions. Upon scopolamine application, increases in pro-saccade SRT $(144.8 \pm 2.1 \mathrm{~ms}$ vs $147.8 \pm 1.9 \mathrm{~ms}, p=0.015)$ and decreases in anti-saccade performance $(77.5 \pm 1.1 \%$ vs $75.4 \pm 1.3 \%, p=0.047$ ) did reach statistical significance. However, these effects were miniscule, and values did not significantly return to control levels when recovery conditions were tested (pro-saccade SRT: $p=0.43$; anti-saccade performance: $p=0.56)$.

\section{Scopolamine decreases overall FRs in DLPFC neurons}

The most conspicuous effect of scopolamine was strong and significant attenuation of neuronal FR in all task epochs. Figure $2 A$ shows the mean FRs of all recorded neurons during the delay, stimulus, and ITI epochs. Scopolamine application attenuated population FR in all epochs (Fig. $2 A ; p<0.0001$, Wilcoxon signed rank test with Holm-Bonferroni correction). This inhibitory effect was dose-dependent (Fig. 2B). Figure $2 B$ shows decreases in normalized mean activity for neurons subject to various doses of scopolamine. Four doses were defined to exemplify the progressive effect of scopolamine dosage. To determine whether the effects of scopolamine were selectively physiological in nature, and not a consequence of loss of isolation or other unrelated effects, we examined recovery after cessation of drug application in 44 neurons. Figure $2 C$ shows the normalized mean FRs for scopolamine application followed by recovery for 44 neurons. During recovery after scopolamine-induced suppression, population activity was significantly greater than during the scopolamine conditions 
( $p=0.00024$, Wilcoxon signed rank test with HolmBonferroni correction).

\section{Scopolamine reduces rule selectivity in the delay epoch of DLPFC neurons}

We examined the rule selectivity of DLPFC neuronal firing before and after scopolamine application. Figure $3 \mathrm{~A}$ shows an example of scopolamine administration on a single rule-selective neuron. Rasters and spike density functions for pro-saccade (blue traces) and anti-saccade (orange traces) trials are shown in control and scopolamine conditions. Rule selectivity was quantified in the delay epoch using the AUROC metric (see Materials and Methods). Iontophoretic administration of scopolamine resulted in a decrease in rule selectivity for this neuron, as determined by AUROC. Importantly, the effect of scopolamine was dosedependent. Incremental doses led to attenuation of FR and rule selectivity in the delay epoch (e.g., FR: control $15.8 \pm 0.6$ spikes/s vs $60 \mathrm{nA}$ scopolamine $10.2 \pm 0.4$ spikes/s, $p<0.0001$, Wilcoxon rank sum test; AUROC: control 0.91 vs $60 \mathrm{nA}$ scopolamine 0.84). This dose-dependent effect on FR is seen consistently in DLPFC neurons, as seen in Figure 3B, which shows 11 neurons given this dosing regimen. Of these 11 neurons, seven were significantly rule-selective based on AUROC analysis. Figure $3 C$ displays how normalized FRs for the preferred and nonpreferred rules in these seven cells changed over the course of the four scopolamine doses. Scopolamine decreased normalized FR for both preferred and nonpreferred rules, with slightly greater decreases for the preferred rule. The difference in effect of scopolamine for preferred versus nonpreferred rules became significant at the 60 $\mathrm{nA}$ dose of scopolamine $(p=0.016$, Wilcoxon signed rank test), when there was substantial suppression of neuronal activity. Thus, scopolamine monotonically decreased firing for both preferred and nonpreferred rules. Figure $3 D$ illustrates the concomitant decrease in rule selectivity over the course of these four doses. Consistent with the effect on preferred and nonpreferred rules, there was a decrease in AUROC that reached significance at $60 \mathrm{nA}$ of scopolamine $(p=0.047$, Wilcoxon signed rank test).

Figure $4 A$ shows another example of a rule-selective neuron. This neuron had greater activity during pro-saccade trials than anti-saccade trials in the delay epoch (pro-saccade: $30.0 \pm 0.84$ spikes/s vs anti-saccade: $20.8 \pm 0.90$ spikes/s, $p<0.0001$, Wilcoxon rank sum test). Scopolamine decreased rule selectivity for this neuron, as determined by AUROC (control 0.85 vs scopolamine 0.68). Of our sample of 135 DLPFC neurons, 30 (17 from Monkey O, 13 from Monkey T; 19 pro-saccade-preferring, 11 anti-saccade-preferring) were found to be significantly ruleselective. Population-normalized spike density functions were constructed for these 30 neurons, which are shown in Figure $4 B$. Scopolamine substantially reduced the population firing and abolished selectivity in the delay epoch. Figure $4 C$ shows a scatter plot of AUROC values (preferred vs nonpreferred rule) in the control condition versus the scopolamine condition. A total of 27 of 30 recorded neurons showed lower AUROC values in the scopolamine condition compared with the control condition. AUROC values were significantly reduced in the scopolamine condition (control: $0.65 \pm 0.018$ vs scopolamine: $0.55 \pm 0.018$, $p=0.00014$, Wilcoxon signed rank test). Next, we examined whether rule selectivity reduction induced by scopolamine was due to changes in preferred or nonpreferred rule firing. Reduction in FR was found to be greater for the preferred rule than for the nonpreferred rule (Fig. $4 D$; preferred: $-9.9 \pm 2.6$ spikes/s vs nonpreferred: $-7.5 \pm 2.2$ spikes/s, $p=0.00015$, Wilcoxon signed rank test).

\section{Scopolamine reduces rule selectivity in the stimulus epoch of DLPFC neurons}

We further examined rule selectivity in the stimulus epoch. Figure $5 A$ shows a DLPFC neuron with rule selectivity in the stimulus epoch, with greater stimulus epoch activity during antisaccade trials (pro-saccade: $9.0 \pm 0.71$ spikes/s vs anti-saccade: $12.1 \pm 0.72$ spikes/s, $p=0.0018$, Wilcoxon rank sum test). Scopolamine suppressed neuronal activity, leading to a reduction in rule-related activity in the stimulus epoch (control: $10.7 \pm 0.52$ spikes/s vs scopolamine: $4.5 \pm 0.30$ spikes/s, $p<0.0001$, Wilcoxon rank sum test). A total of 38 neurons (22 from Monkey $\mathrm{O}$, 16 from Monkey T; 14 pro-saccade-preferring, 24 anti-saccadepreferring) were determined to be significantly rule-selective in the stimulus epoch based on AUROC analysis. The average normalized population spike density functions for these 38 neurons (Fig. 5B) show decrement in selectivity upon scopolamine application. AUROC values decreased after scopolamine application in 32 of 38 neurons (Fig. 5C) with a significant reduction in overall stimulus rule selectivity (control: $0.65 \pm 0.011$ vs scopolamine: $0.54 \pm 0.012, p<0.0001$, Wilcoxon signed rank test). Again, scopolamine decreased rule selectivity by decreasing the FR for the preferred rule more than the nonpreferred rule (Fig. $5 D$; preferred: $-12.6 \pm 2.3$ spikes/s vs nonpreferred: $-7.6 \pm 1.6$ spikes/s; $p<0.0001$, Wilcoxon signed rank test).

\section{Scopolamine reduces saccadic and visual selectivity of DLPFC neurons}

Next, we characterized the effects of scopolamine application on DLPFC neurons displaying motor-related perisaccadic activity and sensory visual activity related to the peripheral stimulus.

Figure $6 A$ is an example of a saccade direction-selective DLPFC neuron. Trials are separated based on the direction of saccades (green trace represents contralateral; purple trace represents ipsilateral). This neuron showed greater perisaccadic activity for the contralateral direction $(23.0 \pm 1.7$ spikes/s $)$ than the ipsilateral direction (18.9 \pm 2.1 spikes/s, $p=0.027$, Wilcoxon rank sum test). Of 135 total neurons, 52 (28 from Monkey O, 24 from Monkey T; 37 contralateral saccade-preferring, 15 ipsilateral saccade-preferring) demonstrated significant saccade direction tuning, based on AUROC analysis. Normalized spike density functions, constructed based on preferred and nonpreferred saccade direction, show a marked reduction in saccade-related firing in the stimulus epoch (Fig. 6B). Scopolamine application significantly decreased saccade direction selectivity in these neurons as shown by the shift in AUROC values (Fig. 6C; control: $0.69 \pm$ 0.011 vs scopolamine: $0.58 \pm 0.014, p<0.0001$, Wilcoxon signed rank test). Loss of selectivity was caused by preferentially greater inhibition to the preferred saccade direction (Fig. $6 D$; preferred: $-13.4 \pm 2.0$ spikes/s vs nonpreferred: $-8.5 \pm 1.7$ spikes/s, $p<$ 0.0001 , Wilcoxon signed rank test).

Figure $7 A$ shows a neuron displaying stimulus epoch selectivity for the contralateral peripheral stimulus. This neuron showed greater activity following contralateral stimulus onset than after the ipsilateral stimulus (contralateral: $29.9 \pm 1.4$ spikes/s vs ipsilateral: $23.6 \pm 1.3$ spikes $/ \mathrm{s}, p=0.0054$, Wilcoxon rank sum test). AUROC analysis of visual selectivity in the stimulus epoch revealed 36 neurons with significant hemispheric discriminability to stimulus presentation in the control condition (16 from Monkey O, 20 from Monkey T; 25 contralateral stimulus-preferring, 11 ipsilateral stimulus-preferring). Population-normalized spike 


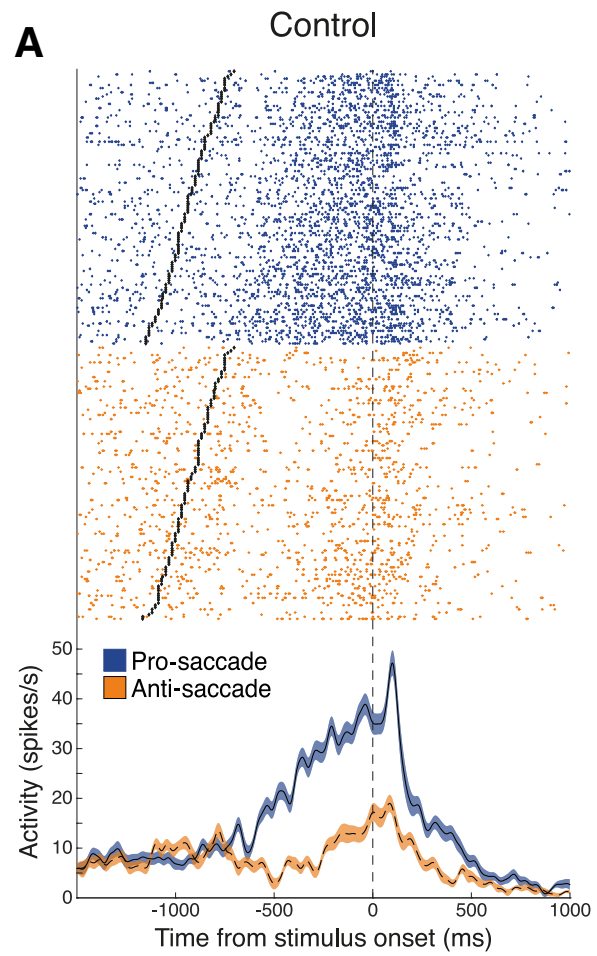

60 nA Scopolamine

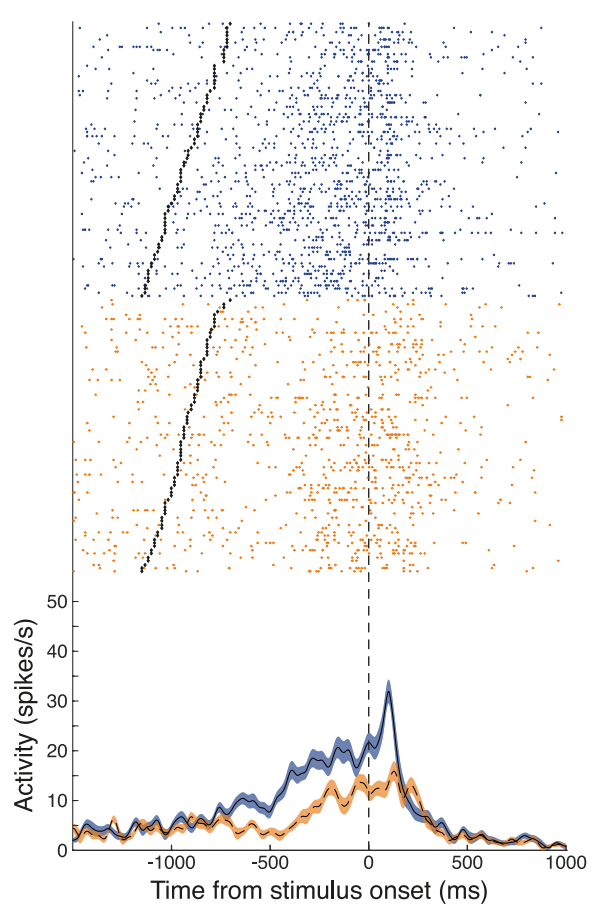

5 nA Scopolamine

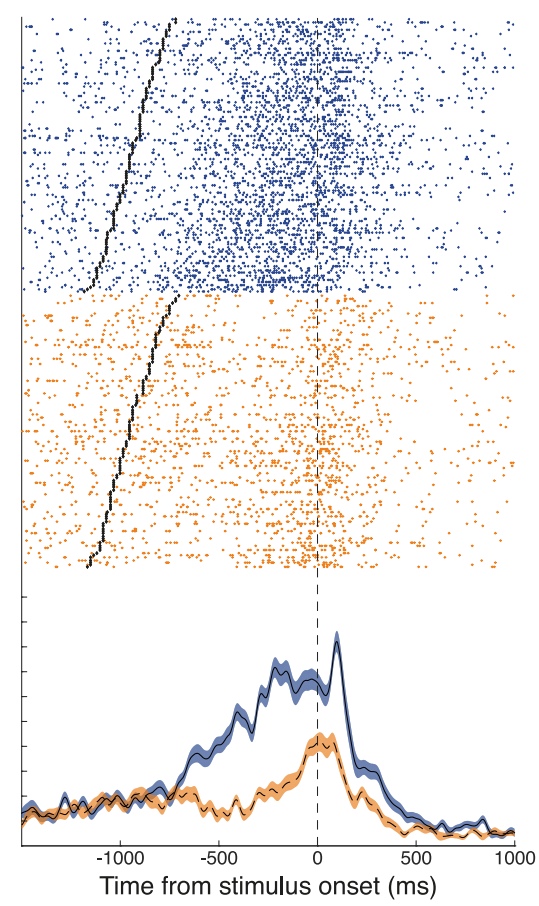

B

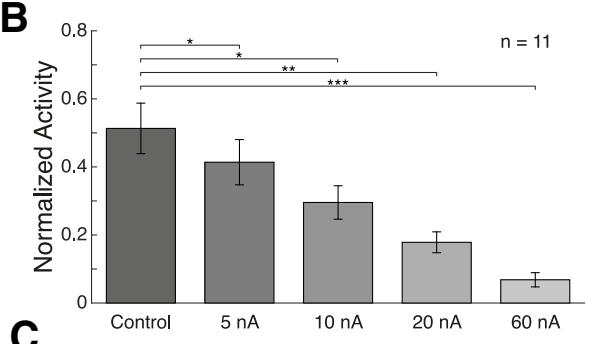

C

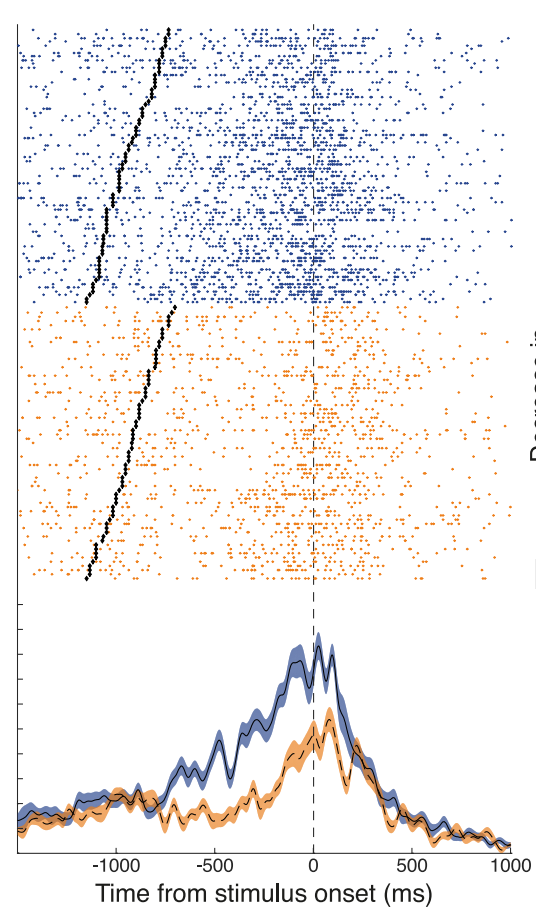

\section{0 nA Scopolamine}

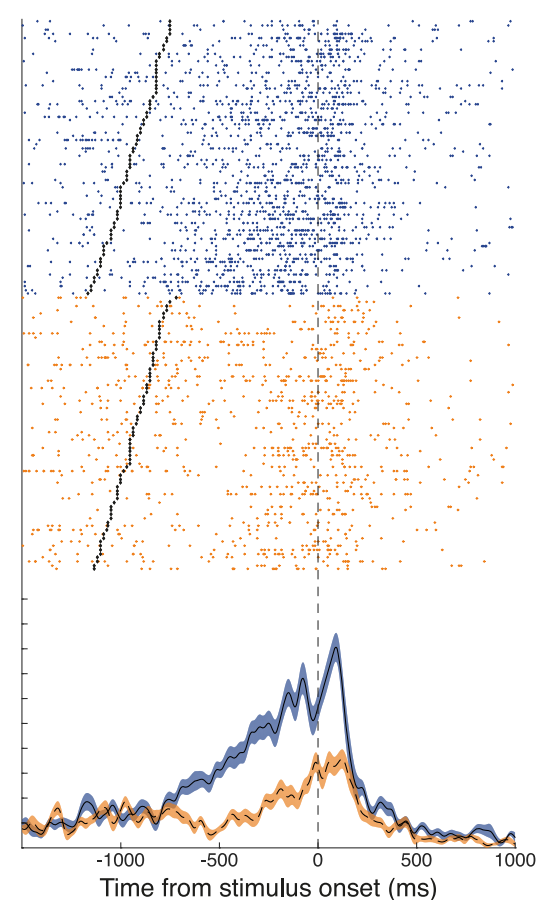

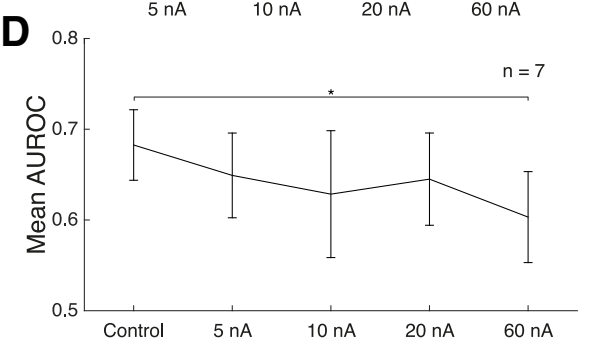

Figure 3. Effect of scopolamine on neuronal firing and task selectivity is dose-dependent. $\boldsymbol{A}$, Single-neuron spike rasters (top panels) and smoothed spike density functions (bottom panels) for pro-saccade (blue) and anti-saccade (orange) rule trials for control, 5, 20, and $60 \mathrm{nA}$ scopolamine, and recovery conditions. Rasters and spike density functions were aligned to stimulus onset. Each row of dots represents a trial raster, and each dot represents a spike. AUROC values are $0.91,0.89,0.89,0.84$, and 0.85 , respectively. $\boldsymbol{B}$, Normalized mean FRs for 11 neurons in which incremental doses of scopolamine were tested. Higher doses of scopolamine led to greater inhibition of FR, compared with control $(5 \mathrm{nA}, p=0.042 ; 10 \mathrm{nA}, p=$ 0.0098; $20 \mathrm{nA}, p=0.0020 ; 60 \mathrm{nA}, 0.00098)$. Sample includes recorded neurons with scopolamine doses of 5, 10, 20, and $60 \mathrm{nA}$. $\boldsymbol{C}$, Decrease in normalized FR for preferred and nonpreferred rule trials of 7 neurons with significant rule selectivity, as determined by AUROC analysis, and given the aforementioned dosing regimen (60 $\mathrm{nA}, p=0.016)$. $D$, Mean $A U R O C$ values during the range of scopolamine doses applied. At $60 \mathrm{nA}$ scopolamine, mean AUROC is significantly attenuated, compared with control values (60 $\mathrm{nA}, p=0.047)$. Error bars indicate SEM. ${ }^{*} p<0.05,{ }^{* *} p<0.005,{ }^{* * *} p<0.001$ (Wilcoxon signed rank test). FRs were normalized as described (see Materials and Methods). 

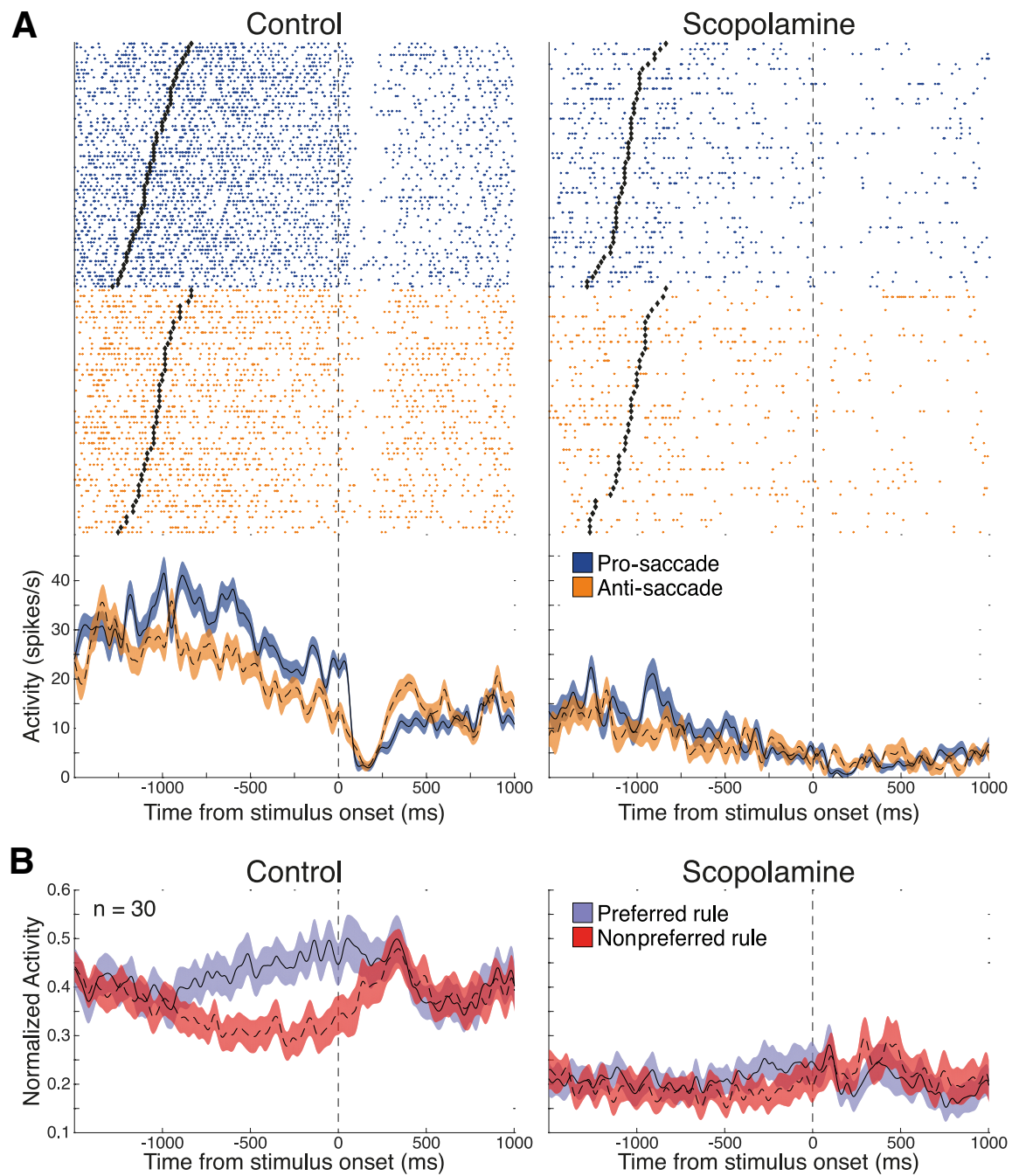

C

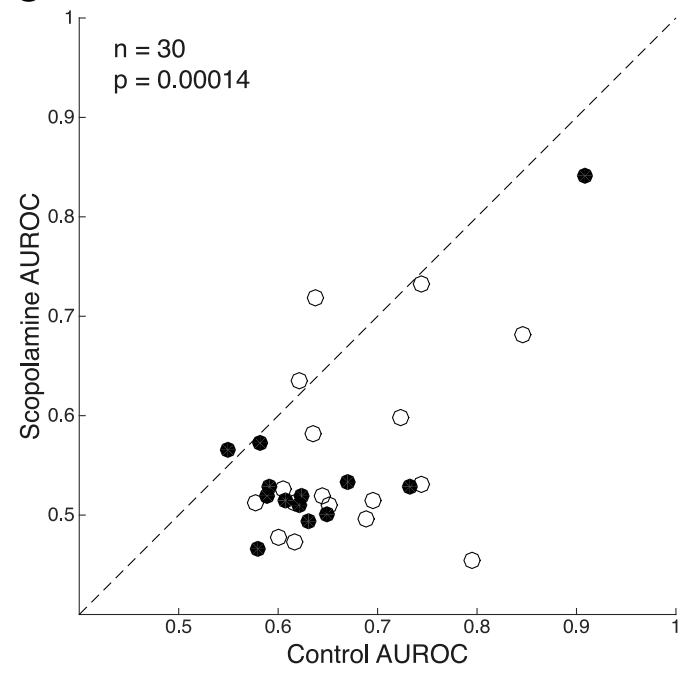

D

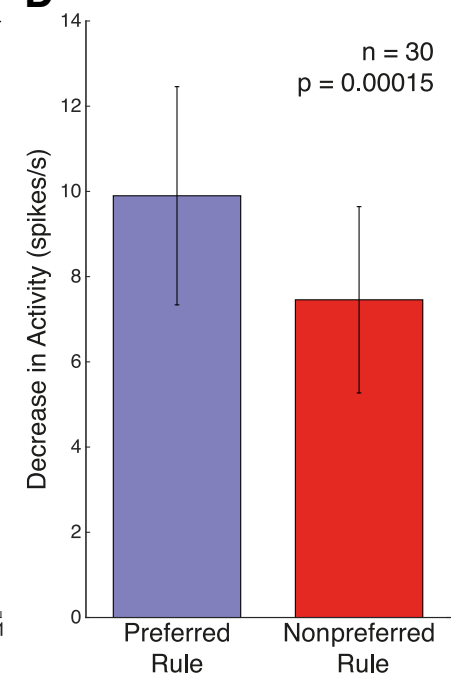

Figure 4. Effect of scopolamine on rule selectivity in the delay epoch. $\boldsymbol{A}$, Single-neuron spike rasters and smoothed spike density functions of pro-saccade (blue) and anti-saccade (orange) rule trials, for both control and $70 \mathrm{nA}$ scopolamine conditions. Delay epoch begins at offset of rule cue (black diamonds) and ends $70 \mathrm{~ms}$ after stimulus onset. $\boldsymbol{B}$, Normalized population spike density functions of preferred (blue) and nonpreferred (red) rule activity in control (left) and scopolamine (right) conditions for 30 significantly rule-selective neurons. Scopolamine decreased both FR for preferred and nonpreferred rule trials and rule discriminability in the delay epoch. C, Scatter plot of control AUROC values (abscissa; open circles represent Monkey 0; filled circles represent Monkey T) compared with AUROC values in the scopolamine condition (ordinate). Dashed line indicates equality line. Greate AUROC deviation from 0.5 indicates greater selectivity for the preferred rule. AUROC values after scopolamine application were density functions of these visual neurons, shown in Figure $7 B$, demonstrate the pronounced suppression induced by scopolamine. AUROC values for these neurons were significantly decreased upon scopolamine administration (Fig. $7 C$; control: $0.66 \pm 0.010$ vs scopolamine: $0.54 \pm$ $0.013, p<0.0001$, Wilcoxon signed rank test). This deterioration of visual selectivity was again due to greater collapse in excitation for the preferred stimulus direction compared with the nonpreferred stimulus direction (Fig. 7D; preferred: $\quad-10.9 \pm 2.0$ spikes/s vs nonpreferred: $-6.8 \pm 1.6$ spikes $/ \mathrm{s} ; p<$ 0.0001, Wilcoxon signed rank test).

\section{Scopolamine effects on units showing} selectivity for multiple task aspects

PFC units generally display complex activity related to task attributes during cognitive performance, whereby single units may display selective activity related to different task aspects (Asaad et al., 2000). After determining neuron selectivity in our population for rule-related selectivity in delay and stimulus epochs, saccade direction selectivity, and visual stimulus direction selectivity, we also examined scopolamine effects on selectivity in neuronal firing for multiple aspects of the task. We identified units that showed significant selectivity in the control period for pairwise combinations of the aforementioned task aspects. The objective was to ascertain whether scopolamine had stronger effects on selectivity for one aspect of task-related firing over another. Table 1 shows the overall unit counts displaying selectivity for the various task components and dual selectivity for pairwise combinations of these components. We examined scopolamine-induced changes in AUROCbased selectivity for constituent components in these units showing compound selectivity and compared them using the Wilcoxon signed rank test (for example, in units showing significant selectivity for both rule and saccade direction, we compared scopolamine-induced change in rule AUROC and change in saccade direction AUROC). Overall, we found no selective effects of scopolamine on selectivity for particular aspects of the task over other aspects in such units with complex selectivity pro-

below the equality line, indicating reduction in rule selectivity. Population AUROC values were significantly reduced by scopolamine. D, Scopolamine elicited a stronger decrease in population FR for the preferred rule in the delay epoch, compared with the nonpreferred rule. Error bars indicate SEM. Significance was determined by Wilcoxon signed rank test. 

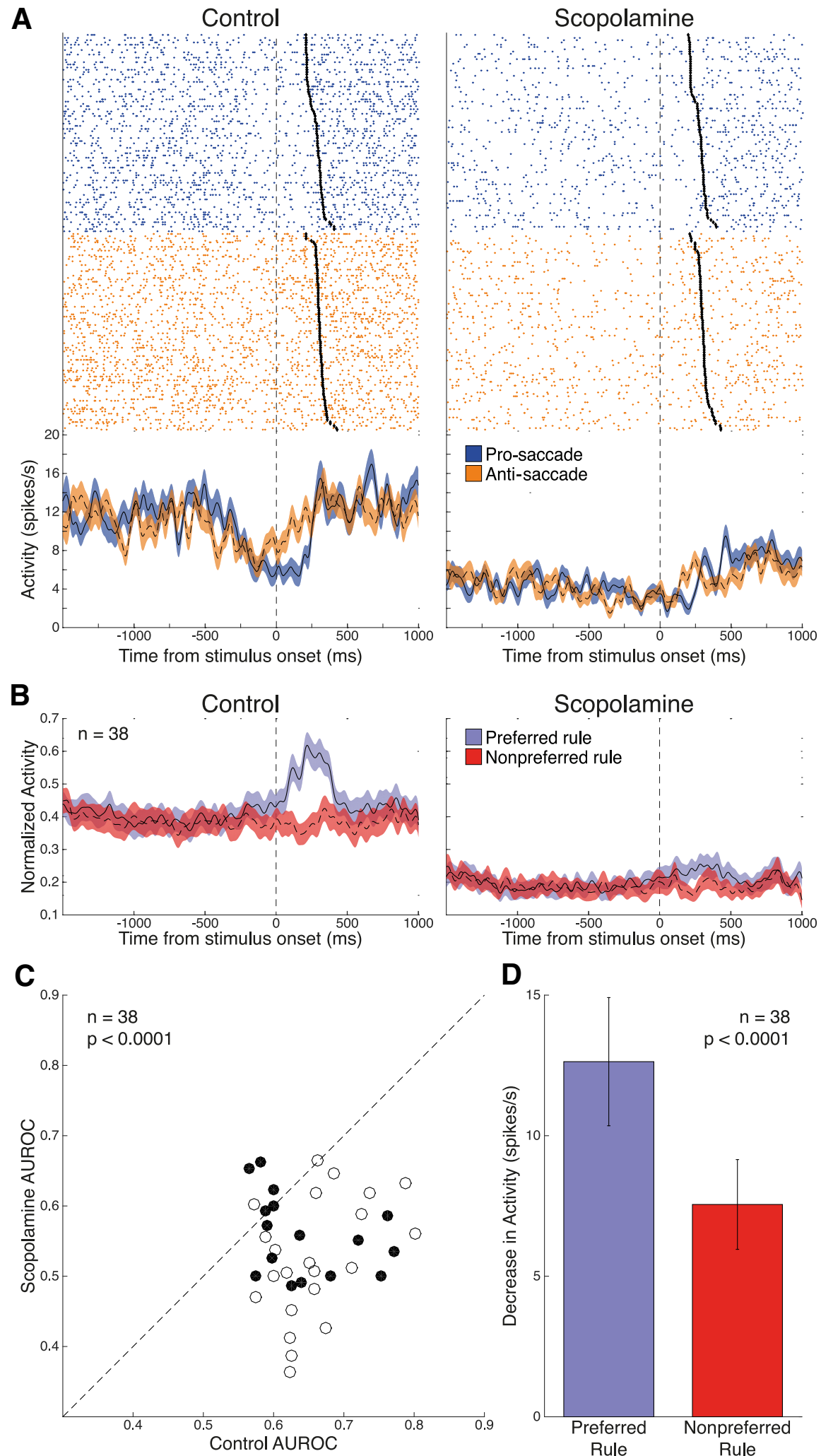

D

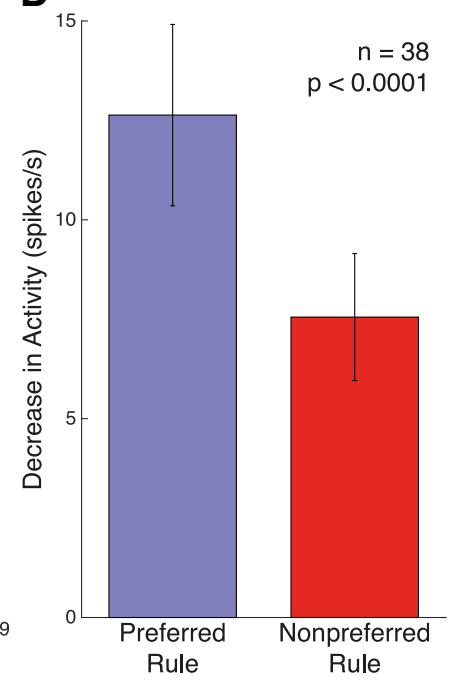

Figure 5. Effect of scopolamine on rule selectivity in the stimulus epoch. $\boldsymbol{A}$, Single-neuron spike rasters and smoothed spike density functions of pro-saccade and anti-saccade rule trials, for both control and $15 \mathrm{nA}$ scopolamine conditions. Stimulus epoch begins $70 \mathrm{~ms}$ after stimulus onset and ends $120 \mathrm{~ms}$ after saccade onset (black diamonds). $\boldsymbol{B}$, Normalized population spike density functions of preferred and nonpreferred rule activity in control and scopolamine conditions for 38 significantly rule-selective neurons. Scopolamine decreased both FR for preferred and nonpreferred rule trials and rule discriminability in the stimulus epoch. C, Scatter plot of control AUROC values (open circles represent Monkey 0; filled circles represent Monkey T) compared with AUROC values in the scopolamine condition. AUROC values after scopolamine application were below the equality line, indicating reduction in rule selectivity. Population AUROC values were significantly reduced by scopolamine. D, Scopolamine elicited a stronger files. Thus, scopolamine appears to cause general disruption of all task-related firing attributes of DLPFC units.

Scopolamine does not change reliability of neuronal firing

Because the AUROC is a nonparametric measure accounting for changes both in the mean and the variance of the distributions being compared, we wished to ascertain whether AUROC reductions upon scopolamine application were due to changes in the FR mean or changes in trial-to-trial variability. To exclude possible changes in reliability of neuronal firing, delay epoch Fano factor was calculated, yielding no significant differences between control and scopolamine conditions (pro-saccade: control $2.7 \pm 0.28$ vs scopolamine $2.6 \pm 0.36, p=0.17$; antisaccade: $3.0 \pm 0.36$ vs $2.4 \pm 0.22, p=0.21$, Wilcoxon signed rank test).

\section{Discussion}

The PFC receives substantial inputs from the ascending cholinergic system (Robbins, 2005), which influences learning and memory, attention, arousal, and sensory discrimination (Luchicchi et al., 2014). This study attempts to address a gap in our knowledge of the physiological underpinnings of cholinergic modulation of DLPFC neurons underlying executive functions. We found that local muscarinic blockade of monkey DLPFC markedly suppressed neuronal firing and reduced selectivity for rule-mnemonic, saccadeand sensory-related activity.

Cognitive domains influenced by the cholinergic system are manifold (Klinkenberg and Blokland, 2010; Bubser et al., 2012) and cause a variety of wellexamined behavioral deficits, including spatial (Rupniak et al., 1991; Green et al., 2005) and nonspatial memory (Thienel et al., 2009), attention (Spinelli et al., 2006; Fredrickson et al., 2008; Furey et al., 2008), sensory discrimination (Evans, 1975; Bartus and Johnson, 1976), and rule maintenance (Thomas et al., 2008; Snyder et al., 2014).

The muscarinic system in PFC appears to play a prominent role in WM function. In rats, both microinfusion of scopolamine into medial PFC and ablation of basal forebrain cholinergic projections disrupt WM performance (Chudasama et

decrease in population $F R$ for the preferred rule in the stimulus epoch, compared with the nonpreferred rule. Error bars indicate SEM. Significance was determined by Wilcoxon signed rank test. 
A
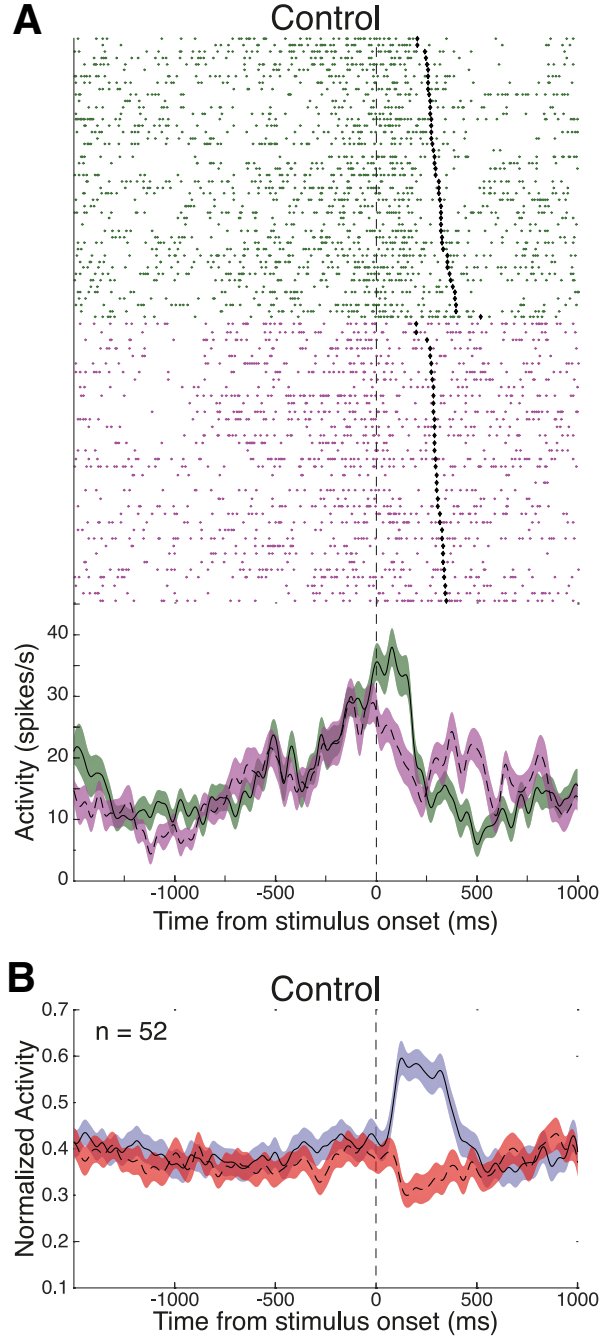

c

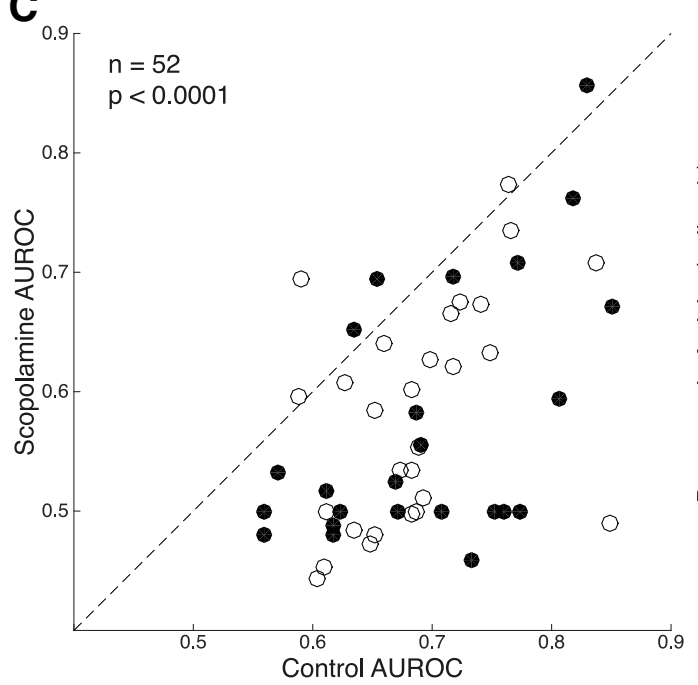

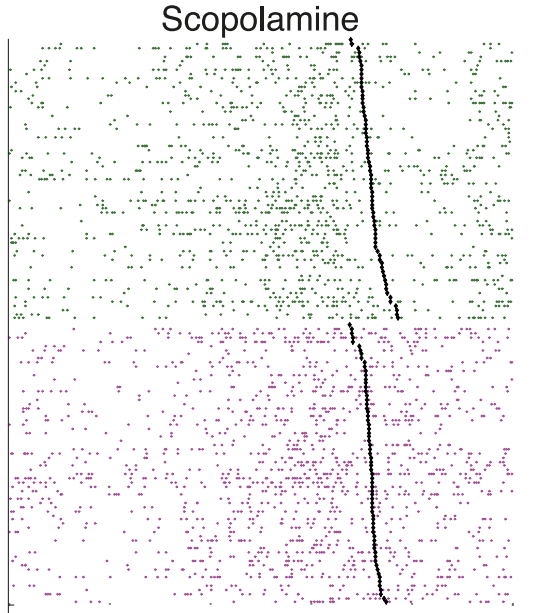

Contralateral saccade

Ipsilateral saccade

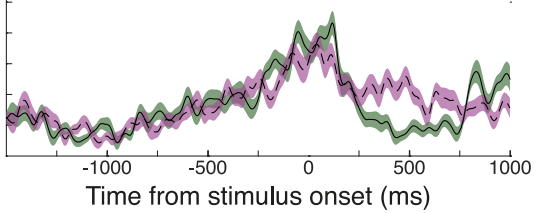

Scopolamine

Preferred saccade direction

Nonpreferred saccadel direction

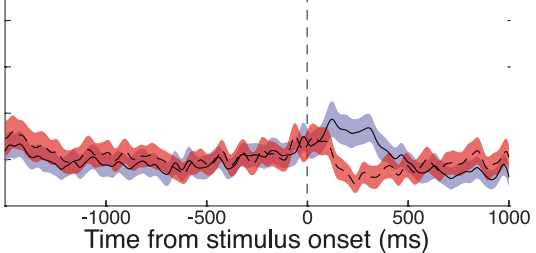

D

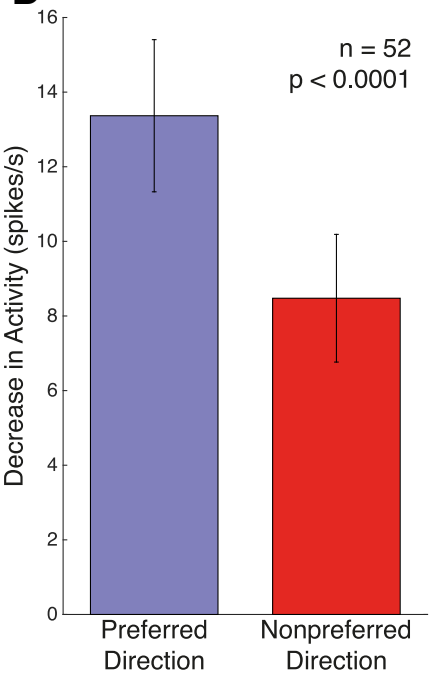

Figure 6. Effect of scopolamine on saccade direction selectivity in the stimulus epoch. $\boldsymbol{A}$, Single-neuron spike rasters and smoothed spike density functions of contralateral (green) and ipsilateral (purple) saccade direction trials, for both control and 70 $\mathrm{nA}$ scopolamine conditions. Stimulus epoch begins $70 \mathrm{~ms}$ after stimulus onset and ends $120 \mathrm{~ms}$ after saccade onset (black diamonds). $\boldsymbol{B}$, Normalized population spike density functions of preferred and nonpreferred saccade direction activity in control and scopolamine conditions for 52 significantly saccade direction-selective neurons. Scopolamine decreased both FR for preferred and nonpreferred direction and saccade direction discriminability in the stimulus epoch. C, Scatter plot of control AUROC values (open circles represent Monkey 0; filled circles represent Monkey T) compared with AUROC values in the scopolamine condition. AUROC values after scopolamine application were below the equality line, indicating reduction in saccade direction selectivity. Population

al., 2004). Cholinergic tone is also a prerequisite for intact $\mathrm{WM}$ function in monkey PFC. Prefrontal cholinergic deafferentation using a cholinergic neuronspecific immunotoxin selectively causes delay-length-dependent deficits in WM performance, but not in other cognitively demanding tasks (Croxson et al., 2011). These deficits are consistent with our observed suppression of delay epoch selectivity in rule neurons; and indeed, such suppression may be the basis of the deficits. In agreement with this, a human imaging study found scopolamine-induced degradation in parahippocampal persistent activity (Schon et al., 2005).

The observed scopolamine-induced neuronal suppression herein is in accord with activity in DLPFC after systemic scopolamine administration (Zhou et al., 2011) and V1 after iontophoretic scopolamine application (Herrero et al., 2008). However, Miller and Desimone (1993) found paradoxical increases in stimulusresponsive activity of macaque inferotemporal neurons after systemic scopolamine administration during delayed matchto-sample performance, although spontaneous activity remained unchanged, suggesting that scopolamine-induced suppression is not universal. Indeed, our results suggest that suppression due to systemic muscarinic blockade (Zhou et al., 2011) can be a direct consequence of PFC muscarinic antagonism and not due to indirect network-effects on activity in other brain areas with PFC connectivity.

ACh affects the physiology of macaque MT neurons and their motion discriminability (Thiele et al., 2012), suggesting a role of cholinergic signaling in effective filtering of information (Thiele, 2013). This is also evident from the attenuation of attentional modulation in primary visual cortex by iontophoretic application of scopolamine (Herrero et al., 2008). Here, we examined the effects of muscarinic modulation on neuronal selectivity for mnemonic rule representation in DLPFC. We find general scopolamineinduced neuronal suppression at various doses, in contrast to Herrero et al. (2008), wherein scopolamine selectively attenuated the attentional component of V1 firing. This difference could be due to

AUROC values were significantly reduced by scopolamine. $D$, Scopolamine elicited a stronger decrease in population FR for the preferred saccade direction in the stimulus epoch, compared with the nonpreferred saccade direction. Error bars indicate SEM. Significance was determined by Wilcoxon signed rank test. 


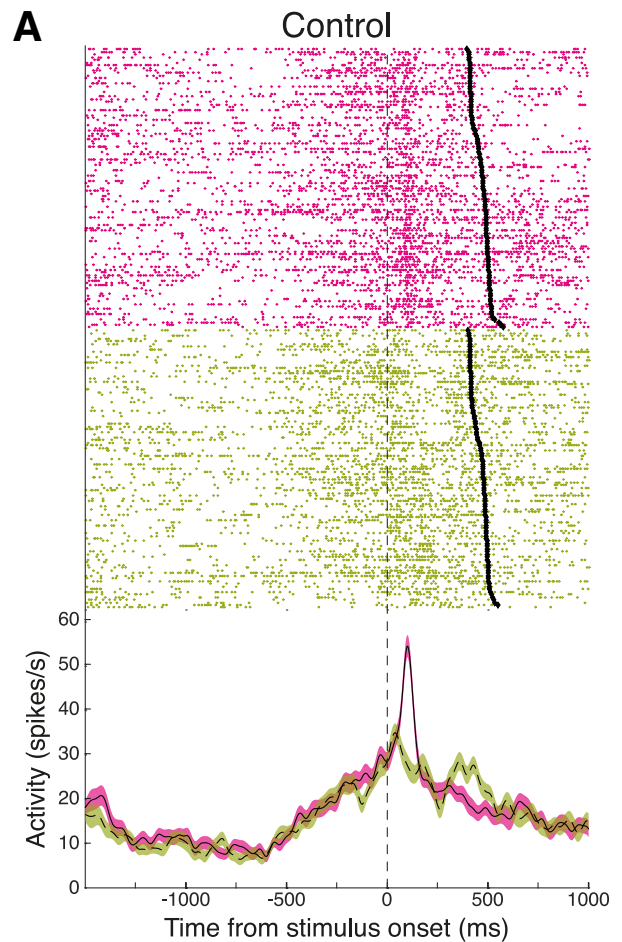

B

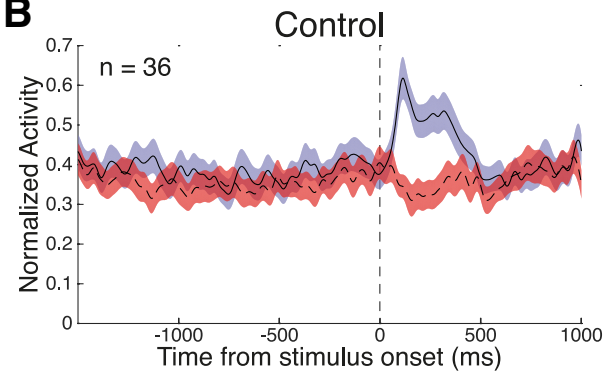

C

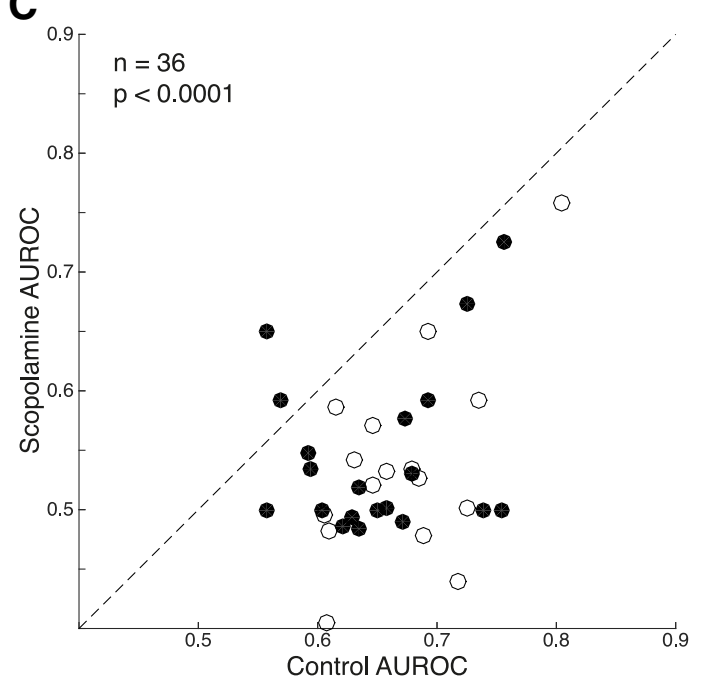

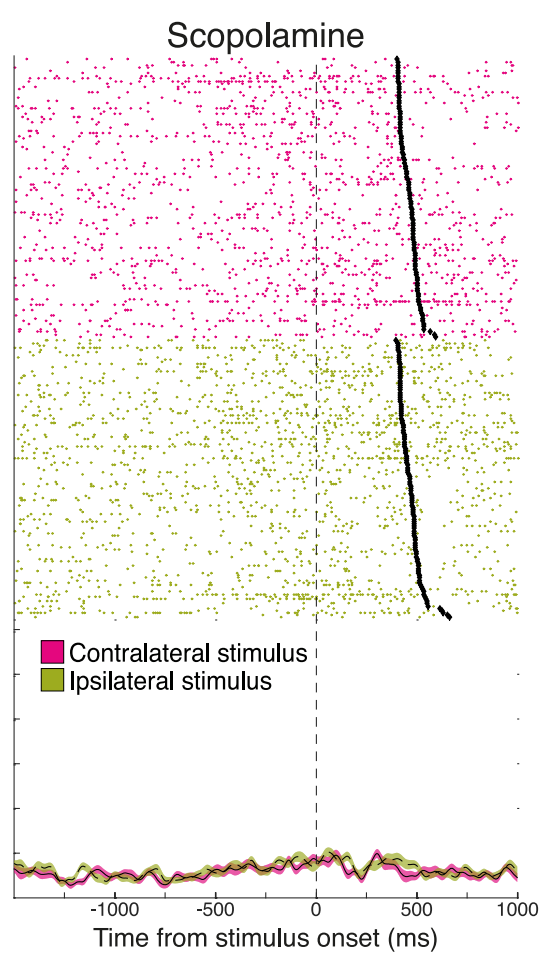

Scopolamine

Preferred stimulus direction Nonpreferred stimulus'direction

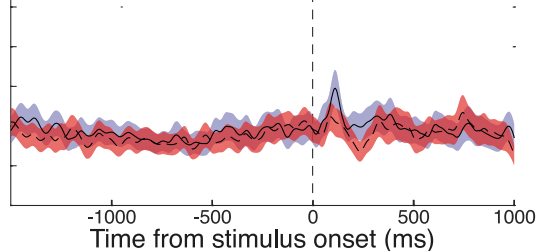

D

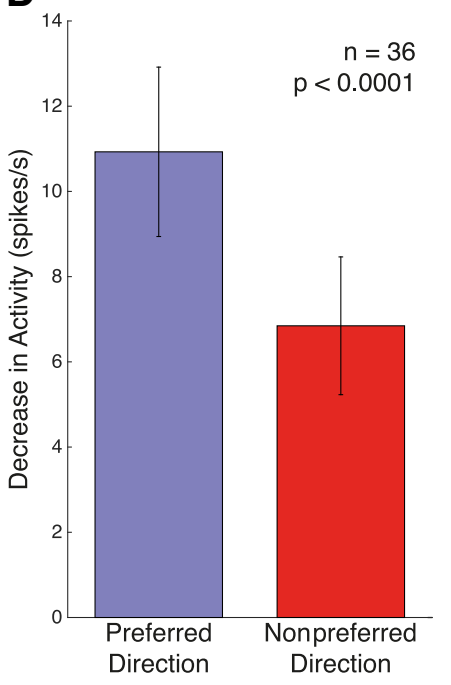

Figure 7. Effect of scopolamine on selectivity for peripheral stimulus direction in the stimulus epoch. $\boldsymbol{A}$, Single-neuron spike rasters and smoothed spike density functions of contralateral (pink) and ipsilateral (green) peripheral stimulus trials, for both control and $15 \mathrm{nA}$ scopolamine conditions. Stimulus epoch begins $70 \mathrm{~ms}$ after stimulus onset and ends $120 \mathrm{~ms}$ after saccade onset (black diamonds). $\boldsymbol{B}$, Normalized population spike density functions of preferred and nonpreferred stimulus direction activity in control and scopolamine conditions for 36 significantly visual stimulus-selective neurons. Scopolamine decreased both FR for preferred and nonpreferred stimulus direction and stimulus direction discriminability in the stimulus epoch. $\boldsymbol{C}$, Scatter plot of control AUROC values (open circles represent Monkey 0; filled circles represent Monkey T) compared with AUROC values in the scopolamine condition. AUROC values after scopolamine application were below the equality line, indicating reduction in direction

differential expression of M1Rs between DLPFC and V1; M1R expression in the latter is higher in parvalbumin-positive interneurons (Disney and Aoki, 2008). Scopolamine-induced reduction in rule selectivity found in this study is consistent with results from Zhou et al. (2011), wherein rule selectivity of DLPFC neurons was degraded during the delay epoch of spatial WM and delayed match-to-sample tasks. They also found scopolamineinduced delay-dependent deficits in behavioral performance, which were interestingly unaffected by distractor load. In contrast to rule selectivity, stimulus selectivity of DLPFC neurons was found to be unaffected by scopolamine (Zhou et al., 2011). Here, we found that peripheral stimulus selectivity was also reduced. We hypothesize that this difference is explained by the different dosing contexts of systemic administration and the focal administration here. Furthermore, suppression of visual-related activity found herein could potentially shed light on the lack of interaction of scopolamine modulation and distractor load found in that study. If visual activity is suppressed, then distractor salience may be comparably reduced, which may contribute to the lack of interaction between distractor load and scopolamine-induced behavioral degradation found in spatial WM (Zhou et al., 2011) and found in delayed match-tosample performance by Miller and Desimone (1993), where scopolamine effects were independent of the number of intervening stimuli (analogous to distractors). This is also in concord with Parikh et al. (2007), who found transient increases in ACh release in rat medial PFC after cue presentation in a cue-detection task, and lack thereof for undetected cues, indicating that salient visual stimuli (e.g., cue or distractor) evoke ACh release, which would then modulate neuronal visually evoked transients. Cholinergic blockade would disrupt this modulation of visualstimulus salience.

We also report that scopolamine suppressed the selectivity of DLPFC neurons possessing perisaccadic activity. Funahashi et al. (1991) observed perisaccadically active neurons in DLPFC, which may be a manifestation of influence on saccade generation circuitry (Watanabe et

selectivity. Population AUROC values were significantly reduced by scopolamine. $\boldsymbol{D}$, Scopolamine elicited a stronger decrease in population $F R$ for the preferred stimulus direction in the stimulus epoch, compared with the nonpreferred stimulus direction. Error bars indicate SEM. Significance was determined by Wilcoxon signed rank test. 
Table 1. Breakdown of neurons showing significant selectivity for multiple task aspects $^{a}$

\begin{tabular}{lllll}
\hline Activity type & $\begin{array}{l}\text { Rule: delay } \\
\text { epoch }\end{array}$ & $\begin{array}{l}\text { Rule: stimulus } \\
\text { epoch }\end{array}$ & $\begin{array}{l}\text { Saccade } \\
\text { direction }\end{array}$ & $\begin{array}{l}\text { Visual stimulus } \\
\text { direction }\end{array}$ \\
\hline Rule: delay epoch & 30 & - & - & - \\
Rule: stimulus epoch & 14 & 38 & - & - \\
Saccade direction & 16 & 20 & 52 & - \\
Visual stimulus direction & 11 & 18 & 23 & 36
\end{tabular}

${ }^{a}$ Shown are unit counts displaying significant AUROC-based selectivity for different task aspects. On the diagonal are the overall numbers of significant units for each individual task aspect (see Figures 4-7). Counts of neurons with significant dual selectivity for the respective activity types are shown. For example, 23 neurons displayed both significant saccade direction selectivity and significant visual stimulus direction selectivity.

al., 2006), corollary discharge feedback about eye position (Sommer and Wurtz, 2008), or saccadic remapping, which updates cortical maps before an impending saccade (Colby et al., 1995).

Zhou et al. (2011) also reported marginal scopolamineinduced changes in saccadic latency $(\sim 5 \mathrm{~ms})$ and increased saccadic dispersion in the delayed response task, but saccades to visual stimuli with zero delay were unaffected. Because this was a systemic study, it is uncertain whether scopolamine's influence on saccadic neurons contributed to these small effects. Subtle changes in WM task saccadic latencies are consistent with effects on DLPFC, which is not directly involved in saccade generation. Similarly, dopamine D1 receptor agonist infusions in DLPFC disrupted oculomotor delayed response while sparing visually guided saccades (Gamo et al., 2015), whereas iontophoretic activation of D2 receptors selectively modulates perisaccadic activity and not delay activity (Williams and Goldman-Rakic, 1995; Wang et al., 2004). Thus, the contribution of neurons with perisaccadic activity to DLPFC circuitry and behavioral performance is fraught with interest, and further elucidation of neuromodulatory influences on these cells is required. Our results suggest that, in addition to other neurotransmitter systems, muscarinic receptors also modulate perisaccadic DLPFC activity.

Slice physiology also supports a putative cholinergic role in the physiology of recurrent activity (Egorov et al., 2002), which is considered the basis of persistent activity in the delay period of WM tasks (Goldman-Rakic, 1995).

Microiontophoretic and systemic injection studies of other modulatory systems, such as catecholaminergic (Wang et al., 2004; Vijayraghavan et al., 2007; Gamo et al., 2010), nicotinic (Yang et al., 2013), serotonergic (Williams et al., 2002), and glutamatergic receptors (Skoblenick and Everling, 2012; Wang et al., 2013), have yielded valuable insights upon the physiological basis of neuromodulation of cognitive circuitry. An emerging focus in the study of cognitive neuromodulation is the dendritic spine of PFC pyramidal cells, where a constellation of receptors, ion channels, and intracellular signaling molecules are found in proximity, acting by diverse mechanisms to augment or shunt spinal synaptic input and its influence on excitability, leading to a form of ongoing plasticity termed dynamic network connectivity (Arnsten et al., 2012). Two main subtypes of muscarinic receptors mediate cholinergic modulation in PFC: the $\mathrm{G}_{\mathrm{q}}$-coupled M1- and $\mathrm{G}_{\mathrm{i} / \mathrm{o}}$-coupled M2-receptor families (Caulfield, 1993). M1Rs are prominently expressed in PFC postsynaptically (Mrzljak et al., 1993; Medalla and Barbas, 2012) and have mostly depolarizing effects (Levey, 1996), whereas the M2 receptor mainly functions as an autoreceptor influencing presynaptic ACh and other neurotransmitter release (Zhang et al., 2002), although it is also found postsynaptically on both PFC pyramids and interneurons (Mrzljak et al., 1993; Medalla and Barbas, 2012). Thus, scopolamine-induced general suppression found here is likely mediated by M1Rs. M1Rs are expressed in asymmetric synapses on PFC spines (Mrzljak et al., 1993), well positioned to augment synaptic inputs and increase neuronal excitability through closure of KCNQ potassium channels mediating the M-current (Arnsten et al., 2012). Consistent with this hypothesis, iontophoretic KCNQ channel blockade augments persistent activity in macaque DLPFC delay neurons (Wang et al., 2011).

There has been burgeoning interest in pharmacological targeting of muscarinic receptors in the treatment of schizophrenia and Alzheimer's disease. Notably, allelic variants of genes encoding several intracellular messengers, which have been localized to PFC pyramidal spines, have been linked to psychiatric disorders (Erdely et al., 2006; Kirkpatrick et al., 2006). Alleles of PIP5K2A, a phosphoinositol pathway regulator of KCNQ channel function, are linked with schizophrenia (Fedorenko et al., 2008). Thus, $\mathrm{M} 1 \mathrm{R}$ and its downstream mediators offer an attractive target for pharmaceutical intervention in these disorders of cognition. Alzheimer's disease is characterized by degeneration of AChproducing basal forebrain neurons, and postmortem histology has revealed abnormal muscarinic receptor expression in PFC, including decreased M1R protein (Flynn et al., 1995). Schizophrenic patients also have decreased M1R expression in DLPFC (Dean et al., 2002). Additionally, some of the efficacy of clozapine-like atypical antipsychotics can be attributed to muscarinic regulation of dopamine signaling (Bymaster et al., 2003; Tzavara et al., 2004). The M1R agonist xanomeline (Bodick et al., 1997; Shekhar et al., 2008) has been investigated for clinical efficacy in treatment of schizophrenia and Alzheimer's disease, and the muscarinic allosteric modulator 1-((4-cyano-4-(pyri-dine-2yl)piperidin-1-yl)methyl-4-oxo-4 H-quinolizine-3-carboxylic acid (PQCA) ameliorates scopolamine-induced cognitive performance deficits in multiple animal models (Uslaner et al., 2013). The present results further support a role of muscarinic receptors in higher-order cognitive processing in primates and encourage future examination of subtype-specific contributions.

\section{References}

Arnsten AF, Wang MJ, Paspalas CD (2012) Neuromodulation of thought: flexibilities and vulnerabilities in prefrontal cortical network synapses. Neuron 76:223-239. CrossRef Medline

Asaad WF, Rainer G, Miller EK (2000) Task-specific neural activity in the primate prefrontal cortex. J Neurophysiol 84:451-459. Medline

Baddeley AD, Hitch GJ (1974) Working memory. In: The psychology of learning and motivation (Bower GA, ed), pp 47-89. San Diego: Academic.

Barak S, Weiner I (2009) Toward an animal model of an antipsychotic drugresistant cognitive impairment in schizophrenia: scopolamine induces abnormally persistent latent inhibition, which can be reversed by cognitive enhancers but not by antipsychotic drugs. Int J Neuropsychopharmacol 12:227-241. CrossRef Medline

Bartus RT, Johnson HR (1976) Short-term memory in the rhesus monkey: disruption from the anti-cholinergic scopolamine. Pharmacol Biochem Behav 5:39-46. CrossRef Medline

Bodick NC, Offen WW, Levey AI, Cutler NR, Gauthier SG, Satlin A, Shannon HE, Tollefson GD, Rasmussen K, Bymaster FP, Hurley DJ, Potter WZ, Paul SM (1997) Effects of xanomeline, a selective muscarinic receptor agonist, on cognitive function and behavioral symptoms in Alzheimer disease. Arch Neurol 54:465-473. CrossRef Medline

Bubser M, Byun N, Wood MR, Jones CK (2012) Muscarinic receptor pharmacology and circuitry for the modulation of cognition. Handb Exp Pharmacol 208:121-166. CrossRef Medline

Buckley MJ, Mansouri FA, Hoda H, Mahboubi M, Browning PG, Kwok SC, Phillips A, Tanaka K (2009) Dissociable components of rule-guided behavior depend on distinct medial and prefrontal regions. Science 325: 52-58. CrossRef Medline

Bussière T, Giannakopoulos P, Bouras C, Perl DP, Morrison JH, Hof PR (2003) Progressive degeneration of nonphosphorylated neurofilament 
protein-enriched pyramidal neurons predicts cognitive impairment in Alzheimer's disease: stereologic analysis of prefrontal cortex area 9. J Comp Neurol 463:281-302. CrossRef Medline

Bymaster FP, Felder CC, Tzavara E, Nomikos GG, Calligaro DO, McKinzie DL (2003) Muscarinic mechanisms of antipsychotic atypicality. Prog Neuropsychopharmacol Biol Psychiatry 27:1125-1143. CrossRef Medline

Caulfield MP (1993) Muscarinic receptors: characterization, coupling and function. Pharmacol Ther 58:319-379. CrossRef Medline

Chudasama Y, Dalley JW, Nathwani F, Bouger P, Robbins TW, Nathwani F (2004) Cholinergic modulation of visual attention and working memory: dissociable effects of basal forebrain 192-IgG-saporin lesions and intraprefrontal infusions of scopolamine. Learn Mem 11:78-86. CrossRef Medline

Colby CL, Duhamel JR, Goldberg ME (1995) Oculocentric spatial representation in parietal cortex. Cereb Cortex 5:470-481. CrossRef Medline

Croxson PL, Kyriazis DA, Baxter MG (2011) Cholinergic modulation of a specific memory function of prefrontal cortex. Nat Neurosci 14: 1510-1512. CrossRef Medline

Dean B, McLeod M, Keriakous D, McKenzie J, Scarr E (2002) Decreased muscarinicl receptors in the dorsolateral prefrontal cortex of subjects with schizophrenia. Mol Psychiatry 7:1083-1091. CrossRef Medline

Disney AA, Aoki C (2008) Muscarinic acetylcholine receptors in macaque V1 are most frequently expressed by parvalbumin-immunoreactive neurons. J Comp Neurol 507:1748-1762. CrossRef Medline

Egorov AV, Hamam BN, Fransén E, Hasselmo ME, Alonso AA (2002) Graded persistent activity in entorhinal cortex neurons. Nature 420: 173-178. CrossRef Medline

Erdely HA, Tamminga CA, Roberts RC, Vogel MW (2006) Regional alterations in RGS4 protein in schizophrenia. Synapse 59:472-479. CrossRef Medline

Evans HL (1975) Scopolamine effects on visual discrimination: modifications related to stimulus control. J Pharmacol Exp Ther 195:105-113. Medline

Everling S, DeSouza JF (2005) Rule-dependent activity for prosaccades and antisaccades in the primate prefrontal cortex. J Cogn Neurosci 17: 1483-1496. CrossRef Medline

Everling S, Dorris MC, Munoz DP (1998) Reflex suppression in the antisaccade task is dependent on prestimulus neural processes. J Neurophysiol 80:1584-1589. Medline

Everling S, Tinsley CJ, Gaffan D, Duncan J (2002) Filtering of neural signals by focused attention in the monkey prefrontal cortex. Nat Neurosci 5:671-676. CrossRef Medline

Fedorenko O, Strutz-Seebohm N, Henrion U, Ureche ON, Lang F, Seebohm G, Lang UE (2008) A schizophrenia-linked mutation in PIP5K2A fails to activate neuronal M channels. Psychopharmacology 199:47-54. CrossRef Medline

Flynn DD, Ferrari-DiLeo G, Mash DC, Levey AI (1995) Differential regulation of molecular subtypes of muscarinic receptors in Alzheimer's disease. J Neurochem 64:1888-1891. CrossRef Medline

Fredrickson A, Snyder PJ, Cromer J, Thomas E, Lewis M, Maruff P (2008) The use of effect sizes to characterize the nature of cognitive change in psychopharmacological studies: an example with scopolamine. Hum Psychopharmacol 23:425-436. CrossRef Medline

Funahashi S, Bruce CJ, Goldman-Rakic PS (1989) Mnemonic coding of visual space in the monkey's dorsolateral prefrontal cortex. J Neurophysiol 61:331-349. Medline

Funahashi S, Bruce CJ, Goldman-Rakic PS (1991) Neuronal activity related to saccadic eye movements in the monkey's dorsolateral prefrontal cortex. J Neurophysiol 65:1464-1483. Medline

Funahashi S, Bruce CJ, Goldman-Rakic PS (1993) Dorsolateral prefrontal lesions and oculomotor delayed-response performance: evidence for mnemonic "scotomas." J Neurosci 13:1479-1497.

Furey ML, Pietrini P, Haxby JV, Drevets WC (2008) Selective effects of cholinergic modulation on task performance during selective attention. Neuropsychopharmacology 33:913-923. CrossRef Medline

Fuster JM, Alexander GE (1971) Neuron activity related to short-term memory. Science 173:652-654. CrossRef Medline

Gamo NJ, Wang M, Arnsten AF (2010) Methylphenidate and atomoxetine enhance prefrontal function through alpha2-adrenergic and dopamine D1 receptors. J Am Acad Child Adolesc Psychiatry 49:1011-1023. CrossRef Medline

Gamo NJ, Lur G, Higley MJ, Wang M, Paspalas CD, Vijayraghavan S, Yang Y,
Ramos BP, Peng K, Kata A, Boven L, Lin F, Roman L, Lee D, Arnsten AF (2015) Stress impairs prefrontal cortical function via D1 dopamine receptor interactions with hyperpolarization-activated cyclic nucleotidegated channels. Biol Psychiatry pii:S0006-3223(15)00078-5. CrossRef Medline

Goldman-Rakic PS (1995) Cellular basis of working memory. Neuron 14: 477-485. CrossRef Medline

Green A, Ellis KA, Ellis J, Bartholomeusz CF, Ilic S, Croft RJ, Phan KL, Nathan PJ (2005) Muscarinic and nicotinic receptor modulation of object and spatial n-back working memory in humans. Pharmacol Biochem Behav 81:575-584. CrossRef Medline

Green DM, Swets JA (1966) Signal detection theory and psychophysics. New York: Wiley.

Guitton D, Buchtel HA, Douglas RM (1985) Frontal lobe lesions in man cause difficulties in suppressing reflexive glances and in generating goaldirected saccades. Exp Brain Res 58:455-472. Medline

Han ZY, Le Novère N, Zoli M, Hill JA Jr, Champtiaux N, Changeux JP (2000) Localization of nAChR subunit mRNAs in the brain of Macaca mulatta. Eur J Neurosci 12:3664-3674. CrossRef Medline

Herrero JL, Roberts MJ, Delicato LS, Gieselmann MA, Dayan P, Thiele A (2008) Acetylcholine contributes through muscarinic receptors to attentional modulation in V1. Nature 454:1110-1114. CrossRef Medline

Hussein S, Johnston K, Belbeck B, Lomber SG, Everling S (2014) Functional specialization within macaque dorsolateral prefrontal cortex for the maintenance of task rules and cognitive control. J Cogn Neurosci 26: 1918-1927. CrossRef Medline

Jacob SN, Nieder A (2014) Complementary roles for primate frontal and parietal cortex in guarding working memory from distractor stimuli. Neuron 83:226-237. CrossRef Medline

Johnston K, Everling S (2006) Neural activity in monkey prefrontal cortex is modulated by task context and behavioral instruction during delayedmatch-to-sample and conditional prosaccade-antisaccade tasks. J Cogn Neurosci 18:749-765. CrossRef Medline

Johnston K, Levin HM, Koval MJ, Everling S (2007) Top-down controlsignal dynamics in anterior cingulate and prefrontal cortex neurons following task switching. Neuron 53:453-462. CrossRef Medline

Johnston K, DeSouza JF, Everling S (2009) Monkey prefrontal cortical pyramidal and putative interneurons exhibit differential patterns of activity between prosaccade and antisaccade tasks. J Neurosci 29:5516-5524. CrossRef Medline

Kirkpatrick B, Xu L, Cascella N, Ozeki Y, Sawa A, Roberts RC (2006) DISC1 immunoreactivity at the light and ultrastructural level in the human neocortex. J Comp Neurol 497:436-450. CrossRef Medline

Klinkenberg I, Blokland A (2010) The validity of scopolamine as a pharmacological model for cognitive impairment: a review of animal behavioral studies. Neurosci Biobehav Rev 34:1307-1350. CrossRef Medline

Konopaske GT, Lange N, Coyle JT, Benes FM (2014) Prefrontal cortical dendritic spine pathology in schizophrenia and bipolar disorder. JAMA Psychiatry 71:1323-1331. CrossRef Medline

Koval MJ, Lomber SG, Everling S (2011) Prefrontal cortex deactivation in macaques alters activity in the superior colliculus and impairs voluntary control of saccades. J Neurosci 31:8659-8668. CrossRef Medline

Kozak R, Bruno JP, Sarter M (2006) Augmented prefrontal acetylcholine release during challenged attentional performance. Cereb Cortex 16: 9-17. CrossRef Medline

Levey AI (1996) Muscarinic acetylcholine receptor expression in memory circuits: implications for treatment of Alzheimer disease. Proc Natl Acad Sci U S A 93:13541-13546. CrossRef Medline

Levitt JB, Lewis DA, Yoshioka T, Lund JS (1993) Topography of pyramidal neuron intrinsic connections in macaque monkey prefrontal cortex (areas 9 and 46). J Comp Neurol 338:360-376. CrossRef Medline

Liao DL, Hong CJ, Chen HM, Chen YE, Lee SM, Chang CY, Chen H, Tsai SJ (2003) Association of muscarinic $\mathrm{ml}$ receptor genetic polymorphisms with psychiatric symptoms and cognitive function in schizophrenic patients. Neuropsychobiology 48:72-76. CrossRef Medline

Luchicchi A, Bloem B, Viaña JN, Mansvelder HD, Role LW (2014) Illuminating the role of cholinergic signaling in circuits of attention and emotionally salient behaviors. Front Synaptic Neurosci 6:24. CrossRef Medline

Mash DC, White WF, Mesulam MM (1988) Distribution of muscarinic receptor subtypes within architectonic subregions of the primate cerebral cortex. J Comp Neurol 278:265-274. CrossRef Medline

Medalla M, Barbas H (2012) The anterior cingulate cortex may enhance 
inhibition of lateral prefrontal cortex via $\mathrm{m} 2$ cholinergic receptors at dual synaptic sites. J Neurosci 32:15611-15625. CrossRef Medline

Mian MK, Sheth SA, Patel SR, Spiliopoulos K, Eskandar EN, Williams ZM (2014) Encoding of rules by neurons in the human dorsolateral prefrontal cortex. Cereb Cortex 24:807-816. CrossRef Medline

Miller EK, Cohen JD (2001) An integrative theory of prefrontal cortex function. Annu Rev Neurosci 24:167-202. CrossRef Medline

Miller EK, Desimone R (1993) Scopolamine affects short-term memory but not inferior temporal neurons. Neuroreport 4:81-84. CrossRef Medline

Miller EK, Erickson CA, Desimone R (1996) Neural mechanisms of visual working memory in prefrontal cortex of the macaque. J Neurosci 16 : 5154-5167. Medline

Milner B (1963) Effects of different brain lesions on card sorting: the role of the frontal lobes. Arch Neurol 9:90-100. CrossRef

Mrzljak L, Levey AI, Goldman-Rakic PS (1993) Association of m1 and m2 muscarinic receptor proteins with asymmetric synapses in the primate cerebral cortex: morphological evidence for cholinergic modulation of excitatory neurotransmission. Proc Natl Acad Sci U S A 90:5194-5198. CrossRef Medline

Parikh V, Kozak R, Martinez V, Sarter M (2007) Prefrontal acetylcholine release controls cue detection on multiple timescales. Neuron 56: 141-154. CrossRef Medline

Perlstein WM, Carter CS, Noll DC, Cohen JD (2001) Relation of prefrontal cortex dysfunction to working memory and symptoms in schizophrenia. J Psychiatry 158:1105-1113. Medline

Phillis JW (1968) Acetylcholine release from the cerebral cortex: its role in cortical arousal. Brain Res 7:378-389. CrossRef Medline

Pucak ML, Levitt JB, Lund JS, Lewis DA (1996) Patterns of intrinsic and associational circuitry in monkey prefrontal cortex. J Comp Neurol 376: 614-630. CrossRef Medline

Robbins TW (2005) Chemistry of the mind: neurochemical modulation of prefrontal cortical function. J Comp Neurol 493:140-146. CrossRef Medline

Rupniak NM, Samson NA, Tye SJ, Field MJ, Iversen SD (1991) Evidence against a specific effect of cholinergic drugs on spatial memory in primates. Behav Brain Res 43:1-6. CrossRef Medline

Saar D, Grossman Y, Barkai E (2001) Long-lasting cholinergic modulation underlies rule learning in rats. J Neurosci 21:1385-1392. Medline

Sakai K (2008) Task set and prefrontal cortex. Annu Rev Neurosci 31: 219-245. CrossRef Medline

Scarr E, Sundram S, Deljo A, Cowie TF, Gibbons AS, Juzva S, Mackinnon A, Wood SJ, Testa R, Pantelis C, Dean B (2012) Muscarinic M1 receptor sequence: preliminary studies on its effects on cognition and expression. Schizophr Res 138:94-98. CrossRef Medline

Schon K, Atri A, Hasselmo ME, Tricarico MD, LoPresti ML, Stern CE (2005) Scopolamine reduces persistent activity related to long-term encoding in the parahippocampal gyrus during delayed matching in humans. J Neurosci 25:9112-9123. CrossRef Medline

Schroeter ML, Vogt B, Frisch S, Becker G, Barthel H, Mueller K, Villringer A, Sabri O (2012) Executive deficits are related to the inferior frontal junction in early dementia. Brain 135:201-215. CrossRef Medline

Shekhar A, Potter WZ, Lightfoot J, Lienemann J, Dube S, Mallinckrodt C, Bymaster FP, McKinzie DL, Felder CC (2008) Selective muscarinic receptor agonist xanomeline as a novel treatment approach for schizophrenia. J Psychiatry 165:1033-1039. CrossRef Medline

Skoblenick K, Everling S (2012) NMDA antagonist ketamine reduces task selectivity in macaque dorsolateral prefrontal neurons and impairs performance of randomly interleaved prosaccades and antisaccades. J Neurosci 32:12018-12027. CrossRef Medline

Snyder PJ, Lim YY, Schindler R, Ott BR, Salloway S, Daiello L, Getter C, Gordon CM, Maruff P (2014) Microdosing of scopolamine as a "cognitive stress test": rationale and test of a very low dose in an at-risk cohort of older adults. Alzheimers Dement 10:262-267. CrossRef Medline

Sommer MA, Wurtz RH (2008) Brain circuits for the internal monitoring of movements. Annu Rev Neurosci 31:317-338. CrossRef Medline

Spinelli S, Ballard T, Feldon J, Higgins GA, Pryce CR (2006) Enhancing effects of nicotine and impairing effects of scopolamine on distinct aspects of performance in computerized attention and working memory tasks in marmoset monkeys. Neuropharmacology 51:238-250. CrossRef Medline Suzuki M, Gottlieb J (2013) Distinct neural mechanisms of distractor sup- pression in the frontal and parietal lobe. Nat Neurosci 16:98-104. CrossRef Medline

Taffe MA, Weed MR, Gold LH (1999) Scopolamine alters rhesus monkey performance on a novel neuropsychological test battery. Brain Res Cogn Brain Res 8:203-212. CrossRef Medline

Thiele A (2013) Muscarinic signaling in the brain. Annu Rev Neurosci 36: 271-294. CrossRef Medline

Thiele A, Delicato LS, Roberts MJ, Gieselmann MA (2006) A novel electrode-pipette design for simultaneous recording of extracellular spikes and iontophoretic drug application in awake behaving monkeys. J Neurosci Methods 158:207-211. CrossRef Medline

Thiele A, Herrero JL, Distler C, Hoffmann KP (2012) Contribution of cholinergic and GABAergic mechanisms to direction tuning, discriminability, response reliability, and neuronal rate correlations in macaque middle temporal area. J Neurosci 32:16602-16615. CrossRef Medline

Thienel R, Kellermann T, Schall U, Voss B, Reske M, Halfter S, Sheldrick AJ, Radenbach K, Habel U, Shah NJ, Kircher T (2009) Muscarinic antagonist effects on executive control of attention. Int J Neuropsychopharmacol 12:1307-1317. CrossRef Medline

Thomas E, Snyder PJ, Pietrzak RH, Jackson CE, Bednar M, Maruff P (2008) Specific impairments in visuospatial working and short-term memory following low-dose scopolamine challenge in healthy older adults. Neuropsychologia 46:2476-2484. CrossRef Medline

Tzavara ET, Bymaster FP, Davis RJ, Wade MR, Perry KW, Wess J, McKinzie DL, Felder C, Nomikos GG (2004) M4 muscarinic receptors regulate the dynamics of cholinergic and dopaminergic neurotransmission: relevance to the pathophysiology and treatment of related CNS pathologies. FASEB J 18:1410-1412. CrossRef Medline

Uslaner JM, Eddins D, Puri V, Cannon CE, Sutcliffe J, Chew CS, Pearson M, Vivian JA, Chang RK, Ray WJ, Kuduk SD, Wittmann M (2013) The muscarinic M1 receptor positive allosteric modulator PQCA improves cognitive measures in rat, cynomolgus macaque, and rhesus macaque. Psychopharmacology 225:21-30. CrossRef Medline

Vijayraghavan S, Wang M, Birnbaum SG, Williams GV, Arnsten AF (2007) Inverted- $\mathrm{U}$ dopamine $\mathrm{D} 1$ receptor actions on prefrontal neurons engaged in working memory. Nat Neurosci 10:376-384. CrossRef Medline

Wallis JD, Anderson KC, Miller EK (2001) Single neurons in prefrontal cortex encode abstract rules. Nature 411:953-956. CrossRef Medline

Wang M, Vijayraghavan S, Goldman-Rakic PS (2004) Selective D2 receptor actions on the functional circuitry of working memory. Science 303: 853-856. CrossRef Medline

Wang M, Gamo NJ, Yang Y, Jin LE, Wang XJ, Laubach M, Mazer JA, Lee D, Arnsten AF (2011) Neuronal basis of age-related working memory decline. Nature 476:210-213. CrossRef Medline

Wang M, Yang Y, Wang CJ, Gamo NJ, Jin LE, Mazer JA, Morrison JH, Wang XJ, Arnsten AF (2013) NMDA receptors subserve persistent neuronal firing during working memory in dorsolateral prefrontal cortex. Neuron 77:736-749. CrossRef Medline

Watanabe K, Igaki S, Funahashi S (2006) Contributions of prefrontal cue-, delay-, and response-period activity to the decision process of saccade direction in a free-choice ODR task. Neural Netw 19:1203-1222. CrossRef Medline

White IM, Wise SP (1999) Rule-dependent neuronal activity in the prefrontal cortex. Exp Brain Res 126:315-335. CrossRef Medline

Williams GV, Goldman-Rakic PS (1995) Modulation of memory fields by dopamine D1 receptors in prefrontal cortex. Nature 376:572-575. CrossRef Medline

Williams GV, Rao SG, Goldman-Rakic PS (2002) Thephysiological role of5-HT2A receptors in working memory. J Neurosci 22:2843-2854. Medline

Yang Y, Paspalas CD, Jin LE, Picciotto MR, Arnsten AF, Wang M (2013) Nicotinic alpha7 receptors enhance NMDA cognitive circuits in dorsolateral prefrontal cortex. Proc Natl Acad Sci U S A 110:12078-12083. CrossRef Medline

Zhang W, Basile AS, Gomeza J, Volpicelli LA, Levey AI, Wess J (2002) Characterization of central inhibitory muscarinic autoreceptors by the use of muscarinic acetylcholine receptor knock-out mice. J Neurosci 22: 1709-1717. Medline

Zhou X, Qi XL, Douglas K, Palaninathan K, Kang HS, Buccafusco JJ, Blake DT, Constantinidis C (2011) Cholinergic modulation of working memory activity in primate prefrontal cortex. J Neurophysiol 106:2180-2188. CrossRef Medline 